\title{
Fast super-resolution imaging technique and immediate early nanostructure capturing by a photoconvertible
}

\section{fluorescent protein}

Mingshu Zhang ${ }^{1, \#}$, Zhifei Fu ${ }^{1,2, \#}$, Changqing Li ${ }^{1, \#}$, Anyuan Liu ${ }^{1,3}$, Dingming Peng ${ }^{1,2}$, Fudong Xue ${ }^{1,2}$,

Wenting $\mathrm{He}^{1}$, Shan $\mathrm{Gao}^{2,4}$, Fan $\mathrm{Xu}^{4}$, Dan $\mathrm{Xu}^{5}$, Ling Yuan ${ }^{6}$, Fa Zhang ${ }^{4}$, Zhiheng $\mathrm{Xu}^{2,7}$, Tao Xu ${ }^{2,8, *}$,

Pingyong $\mathrm{Xu}^{1,2,8, *}$

${ }^{1}$ Key Laboratory of RNA Biology, Institute of Biophysics, Chinese Academy of Sciences, Beijing, 100101, China;

${ }^{2}$ College of Life Sciences, University of Chinese Academy of Sciences, Beijing, 100149 China;

${ }^{3}$ School of Life Sciences, University of Science and Technology of China, Hefei, Anhui, 230026,

China;

${ }^{4}$ Key Lab of Intelligent Information Processing, Institute of Computing Technology, Chinese Academy of Sciences, Beijing 100190, China;

${ }^{5}$ College of Biological Science and Engineering, Institute of Life Sciences, Fuzhou University, Fuzhou 350116, China;

${ }^{6}$ Center for Medical Genetics, School of Life Sciences, Central South University, Changsha, Hunan 410078, China;

${ }^{7}$ State Key Laboratory of Molecular Developmental Biology, CAS Center for Excellence in Brain Science and Intelligence Technology, Institute of Genetics and Developmental Biology, Chinese Academy of Sciences, Beijing, 100101 China;

${ }^{8}$ National Laboratory of Biomacromolecules, CAS Center for Excellence in Biomacromolecules, Institute of Biophysics, Chinese Academy of Sciences, Beijing, China;

\#These authors contributed equally to this work

*For correspondence: PX: pyxu@ibp.ac.cn. Phone: +86-10-64888808. Fax: +86-10-64888808.

ORCID: 0000-0002-8779-6931.

TX:xutao@ibp.ac.cn. Phone: +86-10-64888524 
Supplementary figures and tables:

\begin{tabular}{|c|c|}
\hline Supplementary Figure 1 & Sequence alignment of pcStar, mEos3.2, mMaple3 and Dendra2 \\
\hline Supplementary Figure 2 & $\begin{array}{l}\text { Sedimentation velocity analytical ultracentrifugation of Dendra2, pcStar, } \\
\text { mEos3.2 and mMaple3 at } 0.05 \mathrm{mM}\end{array}$ \\
\hline Supplementary Figure 3 & Assessment of the oligomeric state of PCFPs by the OSER assay \\
\hline Supplementary Figure 4 & Comparison of stabilities of PCFPs \\
\hline Supplementary Figure 5 & Refolding kinetics of PCFPs in vitro \\
\hline Supplementary Figure 6 & $\begin{array}{l}\text { On-switching rate, mean lifetime and blinking number of red pcStar } \\
\text { protein }\end{array}$ \\
\hline Supplementary Figure 7 & Quick-SIMBA of pcStar with $5 \mathrm{~ms}$ exposure time in fixed U2OS cells \\
\hline Supplementary Figure 8 & Quick-SIMBA of pcStar with $2 \mathrm{~ms}$ exposure time in fixed U2OS cells \\
\hline Supplementary Figure 9 & Comparison of SR images of ER structure by different imaging methods \\
\hline Supplementary Figure 10 & Generation of endogenous DE-cad::pcStar and DE-cad::mEos3.2 flies \\
\hline Supplementary Figure 11 & $\begin{array}{l}\text { Development of Drosophila embryonic lch5 organs visualized by pcStar in } \\
\text { vivo tagged DE-cad }\end{array}$ \\
\hline Supplementary Figure 12 & Drosophila embryonic segments and the DE-cad-labeled lch5 organ \\
\hline Supplementary Figure 13 & Pre-characterization of pixel-dependent noise of sCMOS camera \\
\hline Supplementary Figure 14 & Validation of sCMOS noise calibration \\
\hline Supplementary Figure 15 & Validation of sCMOS algorithm by simulation data \\
\hline Supplementary Figure 16 & Schematic diagram of data partitioning and consolidation \\
\hline Supplementary Table 1 & Statistics for the OSER assay \\
\hline Supplementary Table 2 & Characteristics of PCFPs \\
\hline Supplementary Table 3 & Statistics for photostability of PCFPs \\
\hline Supplementary Table 4 & $\begin{array}{l}\text { Statistics for the protein level of H2B-PCFP-SNAP fusions expressed in } \\
\text { U2OS cells at } 16 \mathrm{~h} \text { after transfection. }\end{array}$ \\
\hline Supplementary Table 5 & $\begin{array}{l}\text { Statistics for the green fluorescent intensity of U2OS cells expressing } \\
\text { H2B-PCFP-SNAP normalized to SNAP-Cell 647-SiR }\end{array}$ \\
\hline Supplementary Table 6 & $\begin{array}{l}\text { Statistics for the photoconversion contrast measurements in U2OS cells } \\
\text { overexpressing H2B-PCFP fusions }\end{array}$ \\
\hline Supplementary Table 7 & $\begin{array}{l}\text { Statistics for the signaling efficiency (red channel) comparison in bacteria } \\
\text { endogenously expressing HU-PCFP fusions }\end{array}$ \\
\hline Supplementary Table 8 & Statistics for the red single molecular properties of PCFPs in vitro \\
\hline Supplementary Table 9 & $\begin{array}{l}\text { Statistics for the red single molecular properties of lifeact-pcStar } \\
\text { overexpressed in U2OS cells }\end{array}$ \\
\hline Supplementary Table 10 & On- and off- switching rates of PCFPs \\
\hline Supplementary Table 11 & Statistics for the SSIM value of the PALM reconstruction results \\
\hline Supplementary Table 12 & $\begin{array}{l}\text { Statistics for the } \tau_{1 / \mathrm{e}} \text { of the SSIM curve of the PALM reconstruction } \\
\text { results }\end{array}$ \\
\hline Supplementary Table 13 & $\begin{array}{l}\text { Parameters used in the data analysis of the sedimentation equilibrium } \\
\text { experiments }\end{array}$ \\
\hline Supplementary Note 1 & Detailed experimental methods \\
\hline Supplementary Note 2 & Quick-SIMBA algorithm \\
\hline
\end{tabular}




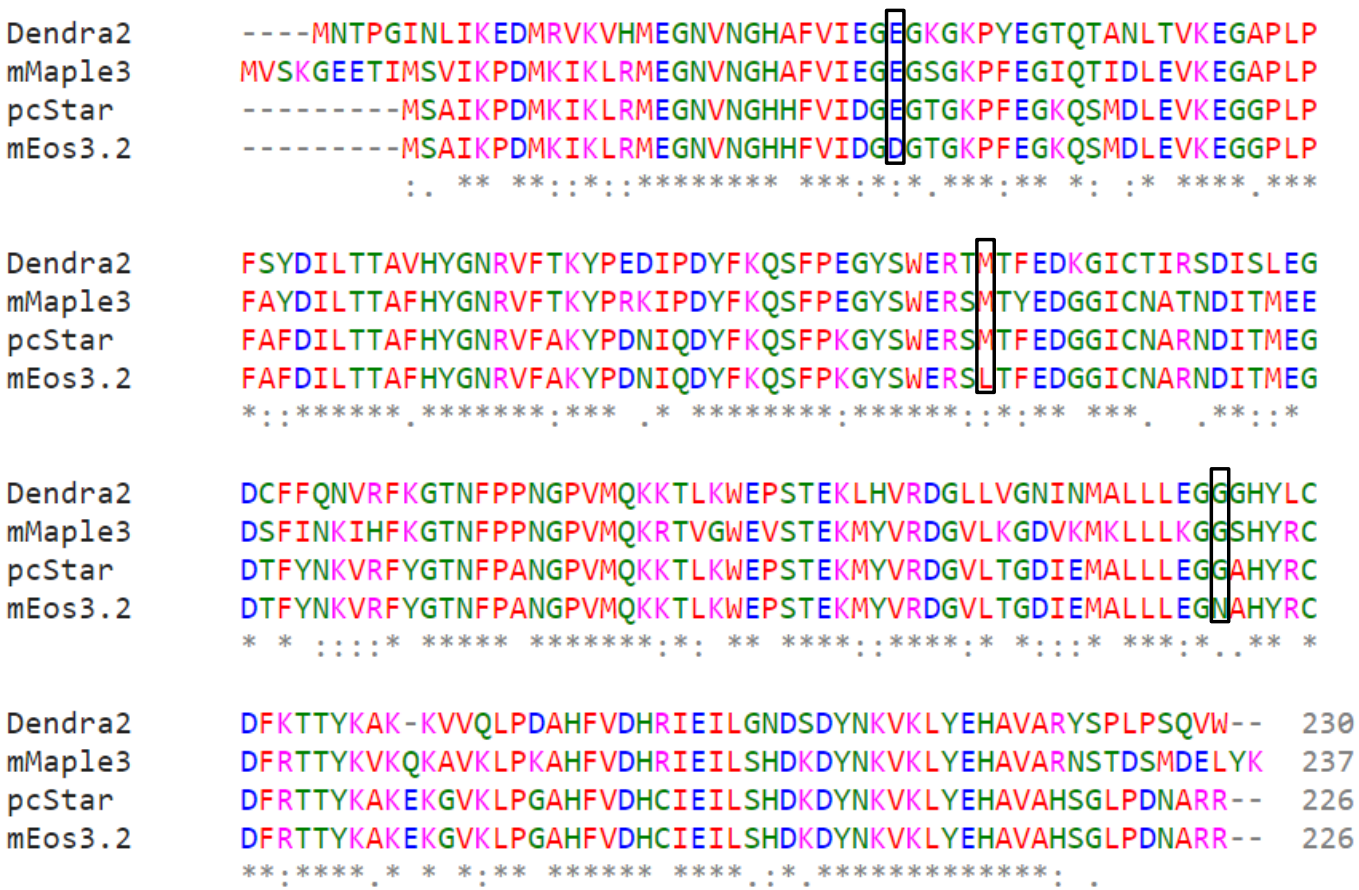

DCFFQNVRFKGTNFPPNGPVMQKKTLKWEPSTEKLHVRDGLLVGNINMALLLEGGGHYLC DSFINKIHFKGTNFPPNGPVMQKRTVGWEVSTEKMYVRDGVLKGDVKMKLLLKG SSHYRC DTFYNKVRFYGTNFPANGPVMQKKTLKWEPSTEKMYVRDGVLTGDIEMALLLEGGAHYRC DTFYNKVRFYGTNFPANGPVMQKKTLKWEPSTEKMYVRDGVLTGDIEMALLLEG NAHYRC * $*:::: * * * * * * * * * * * * * *: *: * * * * * *:: * * * *$ : $* * *::: * * * * * * \ldots * * *$

DFKTTYKAK-KVVQLPDAHFVDHRIEILGNDSDYNKVKLYEHAVARYSPLPSQVW- - 230 DFRTTYKVKQKAVKLPKAHFVDHRIEILSHDKDYNKVKLYEHAVARNSTDSMDELYK 237 DFRTTYKAKEKGVKLPGAHFVDHCIEILSHDKDYNKVKLYEHAVAHSGLPDNARR - - 226 DFRTTYKAKEKGVKLPGAHFVDHCIEILSHDKDYNKVKLYEHAVAHSGLPDNARR - - 226 $* *$ : $* * * * * * *$; $* * * * * * * * * * * *, ; *, * * * * * * * * * * * * *$ :

Supplementary Figure 1 Sequence alignment of pcStar, mEos3.2, mMaple3 and Dendra2. Mutation sites of pcStar are highlighted in black boxes. 

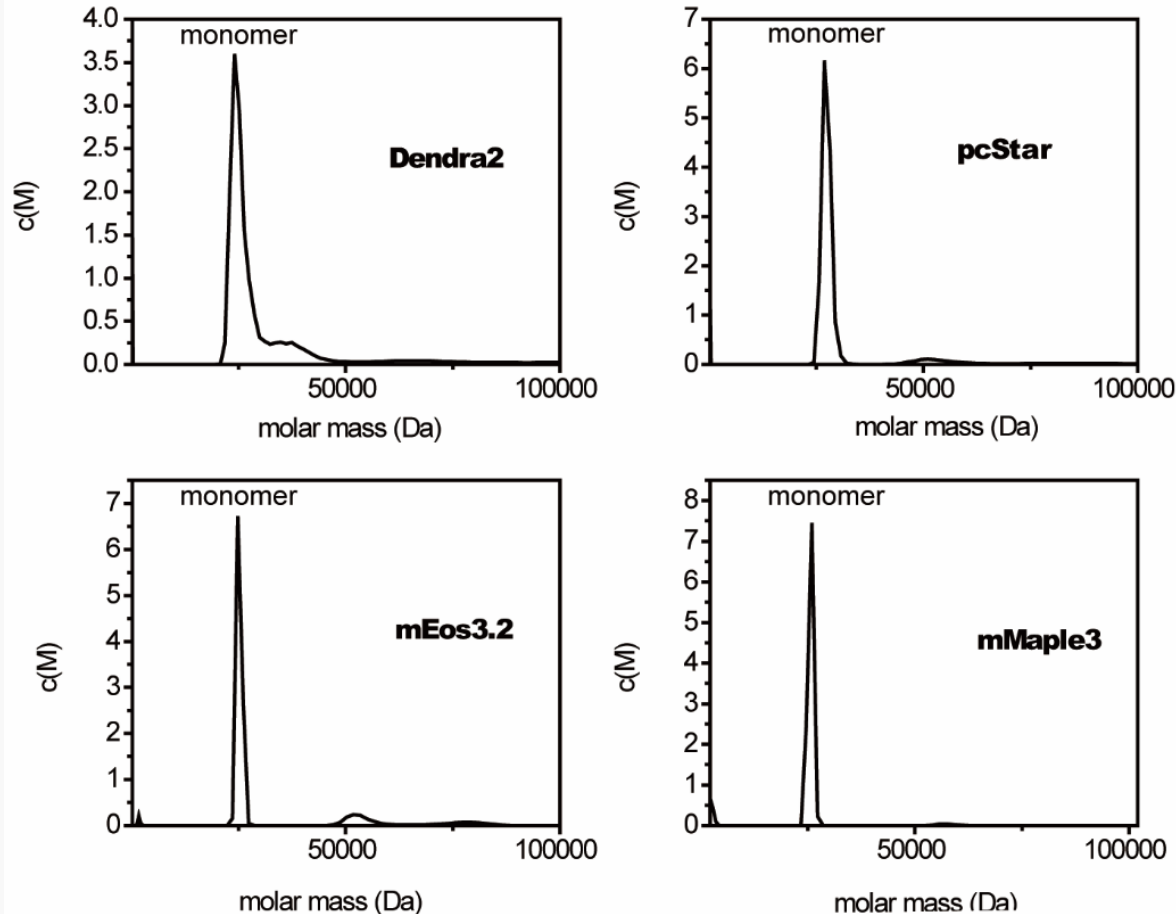

Supplementary Figure 2 Sedimentation velocity analytical ultracentrifugation of Dendra2, pcStar, mEos3.2 and mMaple3 at $0.05 \mathrm{mM}$. The theoretical molecular weight of monomeric Dendra2, pcStar and mEos3.2 and mMaple3 with a $6 \times$ His tag is approximately $30 \mathrm{kD}$. 

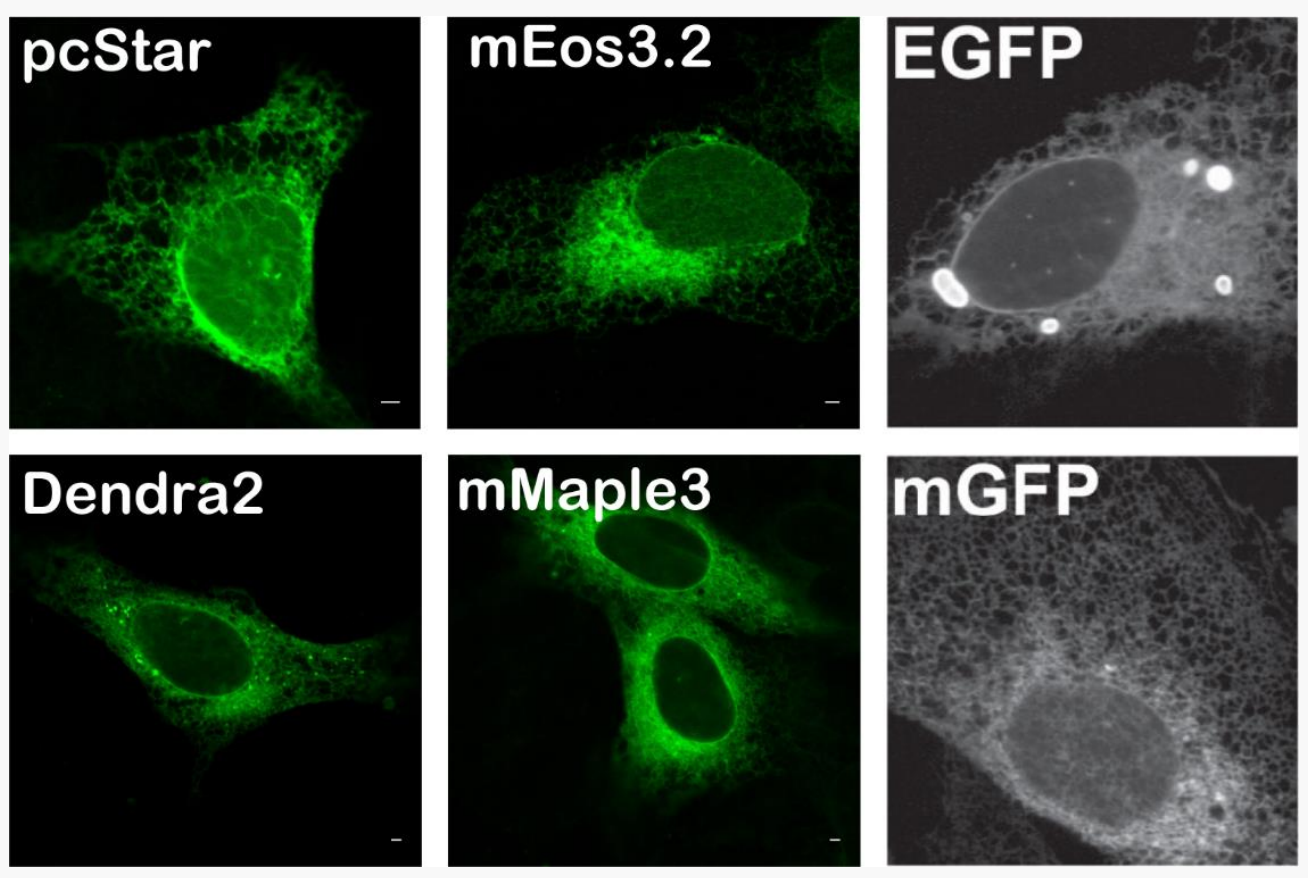

Supplementary Figure 3 Assessment of the oligomeric state of PCFPs by the OSER assay. U2OS cells were transfected with plasmids encoding fusions of ERlocalized CytERM to different PCFPs. Scale bars are $2 \mu \mathrm{m}$. EGFP is a negative control with "ER whorl" structures and mGFP is a positive control with "normal ER"1. 
a

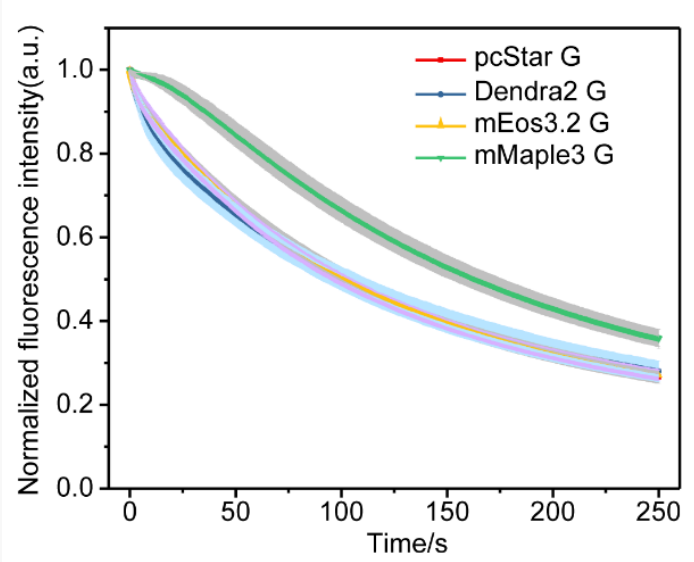

C

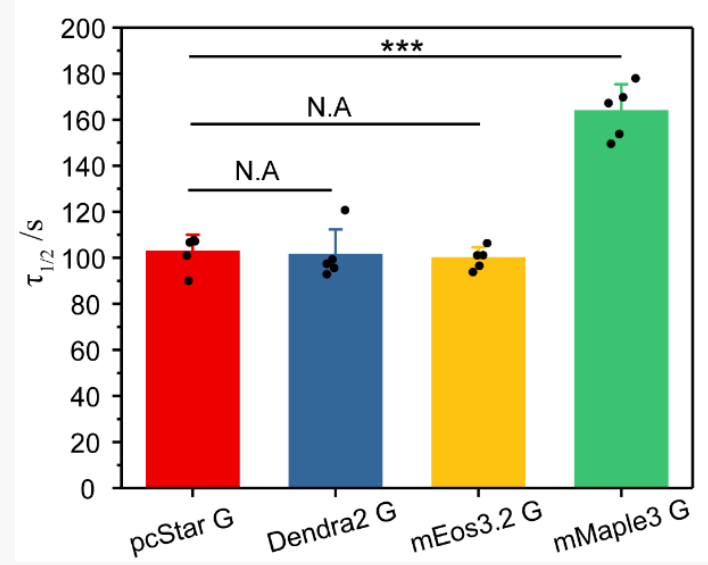

b

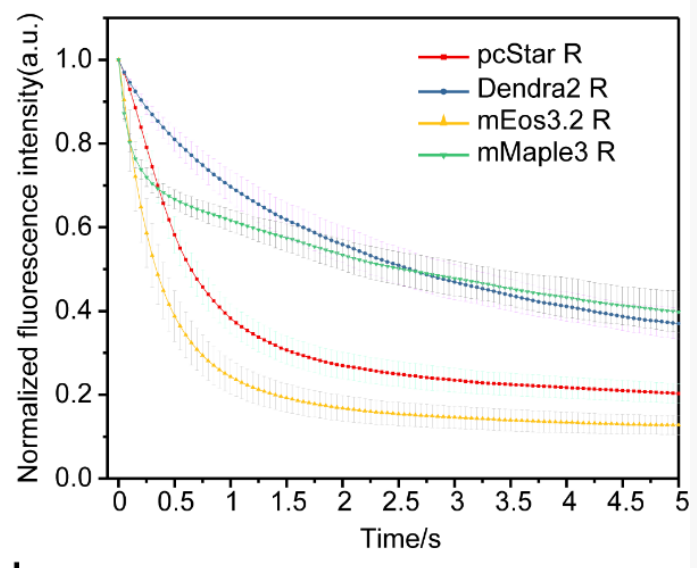

d

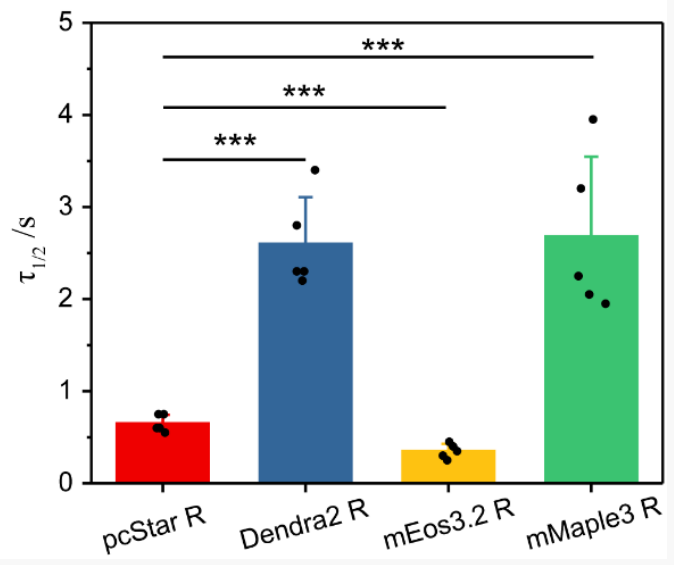

Supplementary Figure 4 Comparison of photostabilities of PCFPs. a,

Photobleaching curves of the green state PCFPs under wide-filed illumination (488 $\mathrm{nm}$ laser: $3 \mathrm{~W} / \mathrm{cm}^{2}$ ). b, Photobleaching curves of the red state PCFPs under wide-filed illumination $\left(561 \mathrm{~nm}\right.$ laser: $\left.300 \mathrm{~W} / \mathrm{cm}^{2}\right)$. c, Statics for the averaged decay half-time of the green state fluorescence intensity. d, Statics for the averaged decay half-time of the red state fluorescence intensity. 

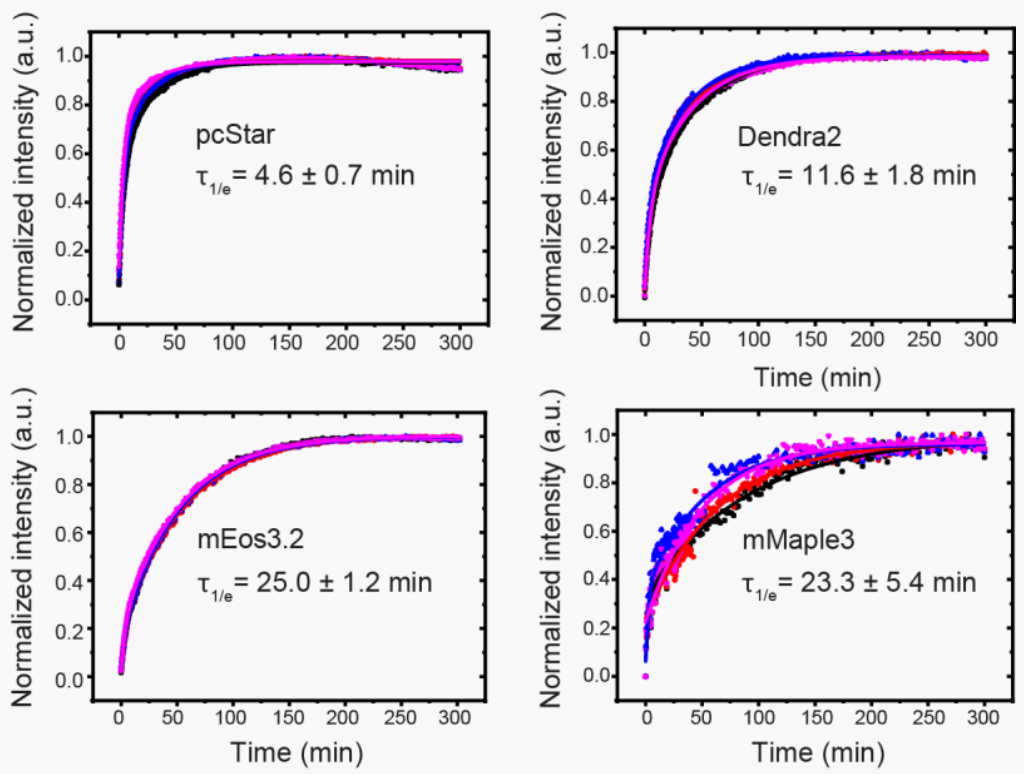

Supplementary Figure 5 Refolding kinetics of PCFPs in vitro. Fluorescence intensity changes of purified proteins in refolding buffer were recorded and normalized in real-time at $25{ }^{\circ} \mathrm{C}$ after heat denaturation. For each sample, data points (dots) from 4 replicates (color coded) were fitted individually by Equation 6 or 7 (curve). The folding/maturation time $\tau_{1 / \mathrm{e}}$ shown represents the mean values \pm standard deviation of $\mathrm{t} 1$ of four replicates. 

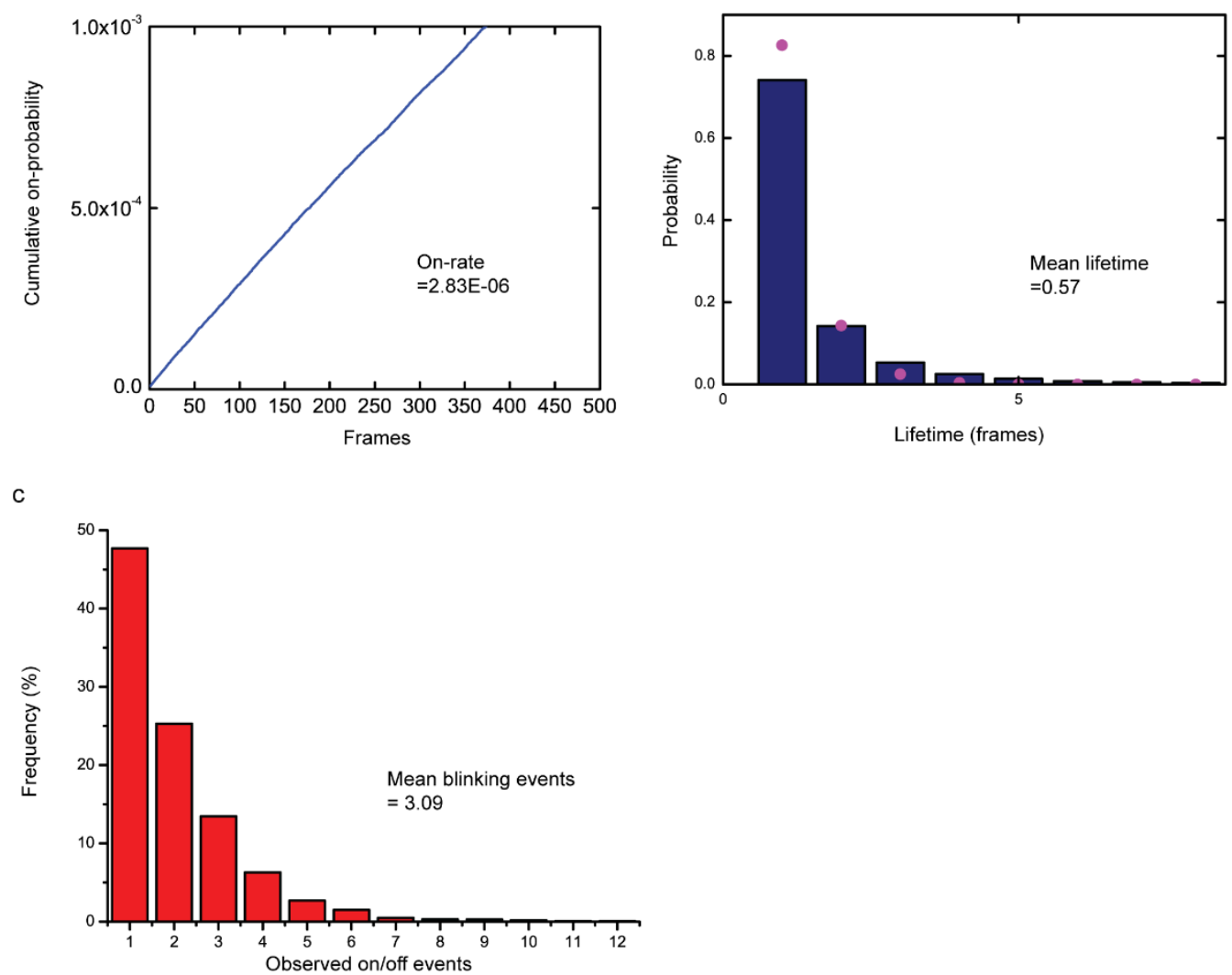

Supplementary Figure 6 On-switching rate, mean lifetime and blinking number of pcStar. a, Cumulative on-switching probability of pcStar overexpressed in U2OS cells as a function of time without activation light. The slope of the line gives the onswitching rate. b, Distribution of the on-state lifetime of pcStar overexpressed in U2OS cells. The blue bars represent measured data, which were fitted with a binned exponential function (magenta dots) $P_{n}=\int_{n-1}^{n}\left(\frac{1}{m}\right) e^{-\frac{x}{m}} d x . \mathrm{m}$ is the mean lifetime, the inverse of which gives the off-switching rate. Each frame corresponds to $50 \mathrm{~ms}$. c, Blinking number distributions of pcStar proteins by in vitro measurement. 

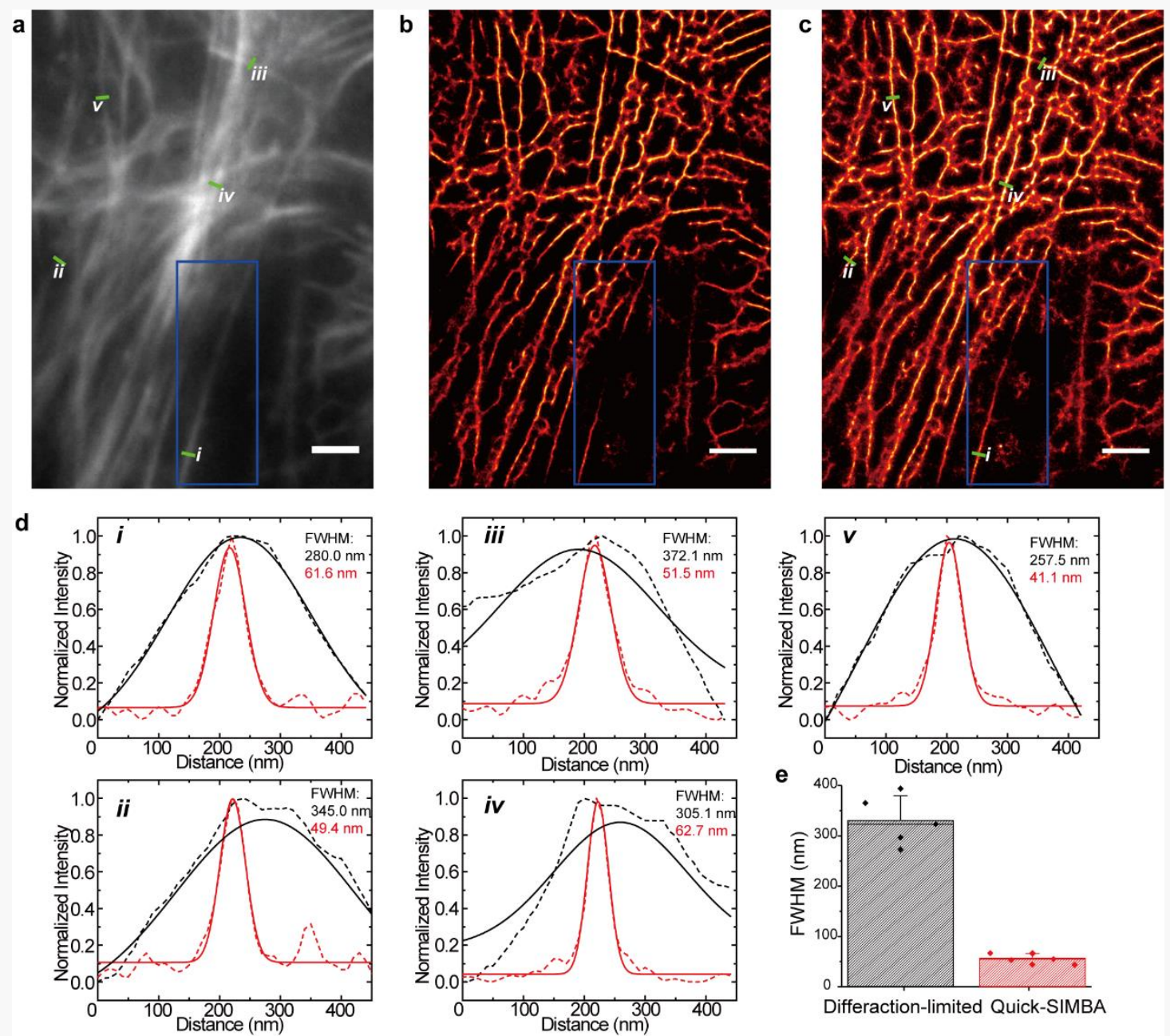

\section{Supplementary Figure 7 Quick-SIMBA of pcStar with 5 ms exposure time in}

fixed U2OS cells. a, Diffraction-limited image represented by the sum of the 50 raw frames. b, Reconstructed image using Quick-SIMBA algorithm without data partitioning and consolidation. c, Reconstructed image using Quick-SIMBA algorithm. d, Cross-section profiles of actin filaments denoted by the green lines in a (black dash line) and $\mathbf{c}$ (red dash line); Gaussian fitting of the cross-section profiles of the green lines in a (black solid line) and $\mathbf{c}$ (red solid line). e, Full width at half maximum (FWHM) of the diffraction-limited image (mean=311.95 $\mathrm{nm}$ ) and the Quick-SIMBA image (mean=53.29 $\mathrm{nm}$ ). The box plot indicates the SD and mean. Scale bars: $2 \mu \mathrm{m}$. 
a

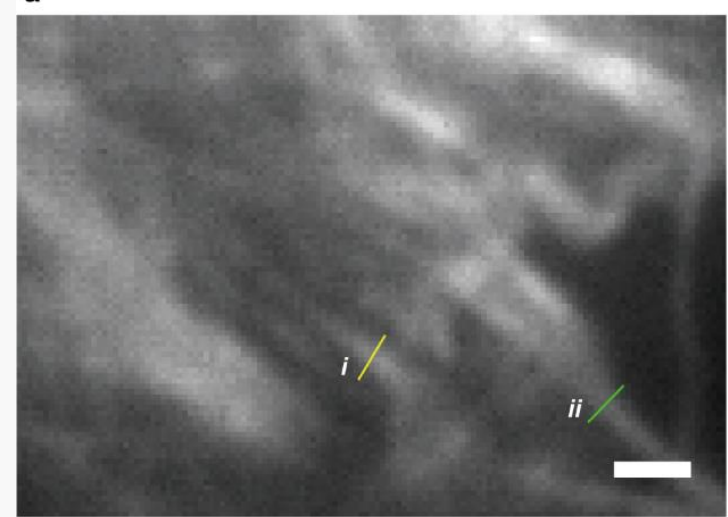

c

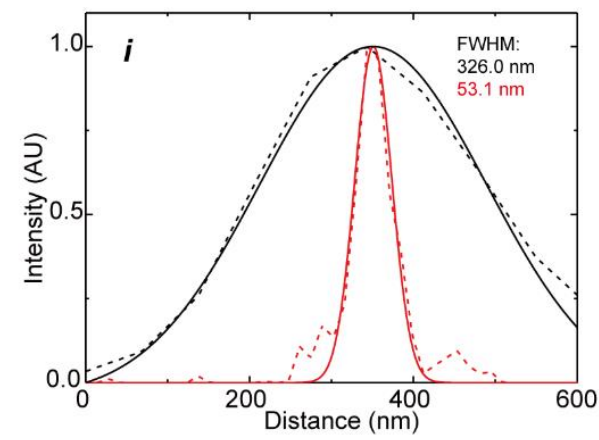

b
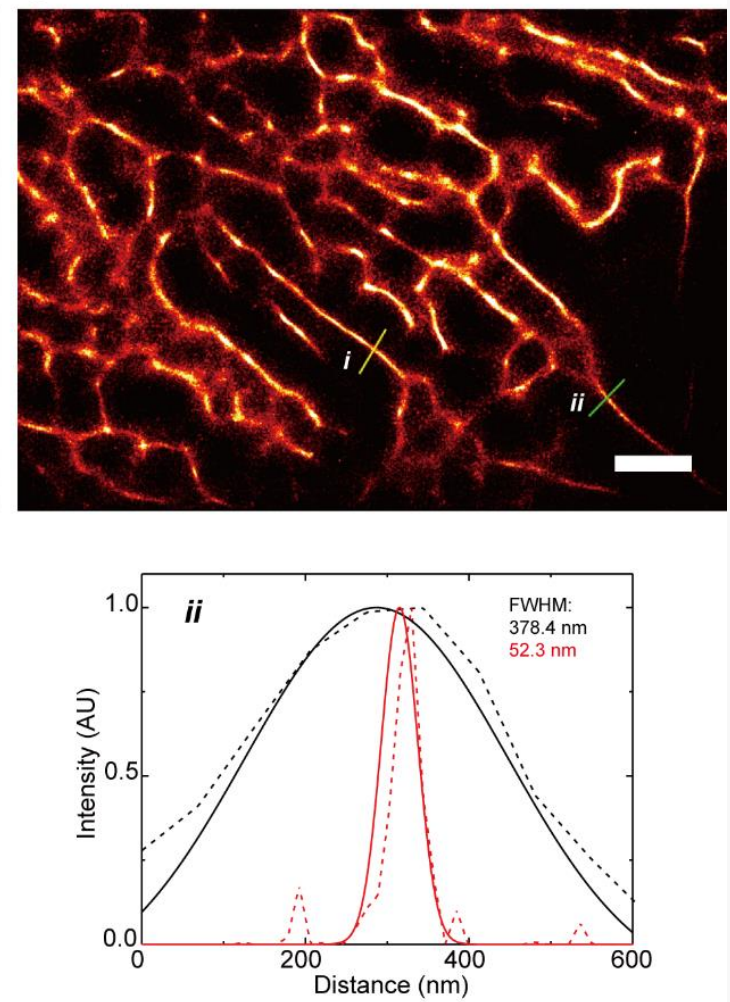

Supplementary Figure 8 Quick-SIMBA of pcStar with 2 ms exposure time in fixed U2OS cells. a, Diffraction-limited image represented by the sum of the 50 raw frames. b, Reconstructed image using Quick-SIMBA algorithm. c, Cross section profiles of actin filaments denoted by the yellow and green lines in a (black dash line) and $\mathbf{b}$ (red dash line); Gaussian fitting of the cross-section profiles of yellow and green lines in $\mathbf{a}$ (black solid line) and $\mathbf{b}$ (red solid line. Scale bars: $1 \mu \mathrm{m}$. 

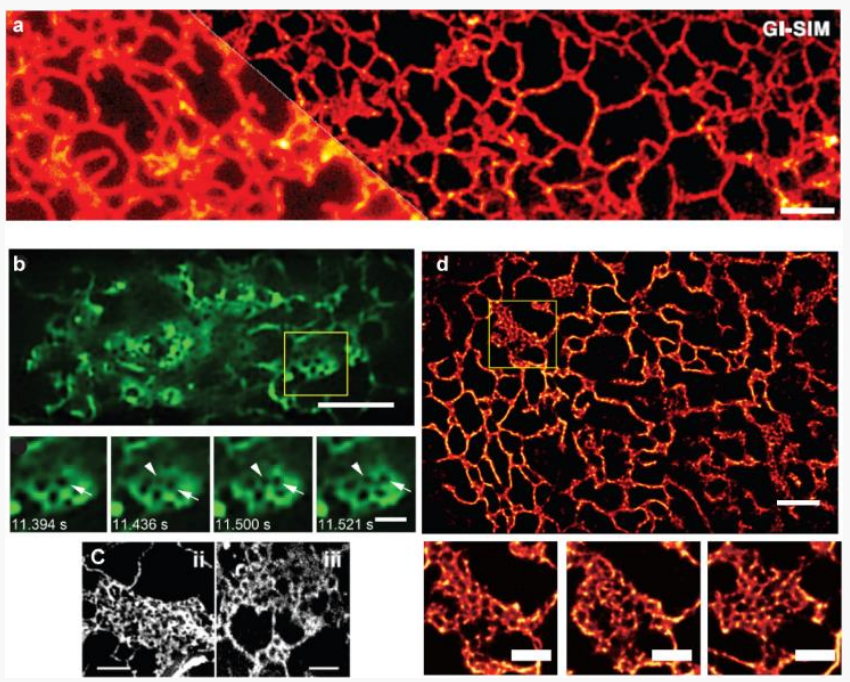

Supplementary Figure 9 Comparison of SR images of ER structure by different imaging methods. a, GI-SIM images of $\mathrm{ER}^{2}$. b, Hessian SIM images of $\mathrm{ER}^{3}$. c(ii), 3D-SIM images of $\mathrm{ER}^{4}$. c(iii), LLS-PAINT images of ER dense tubule matrices ${ }^{4}$ and d, SIMBA images of ER. Scale bars: $2 \mu \mathrm{m}$ (a, b upper, c and $\mathbf{d}$ upper), $1 \mu \mathrm{m}$ (d lower) and $0.5 \mu \mathrm{m}$ (b lower). 
a
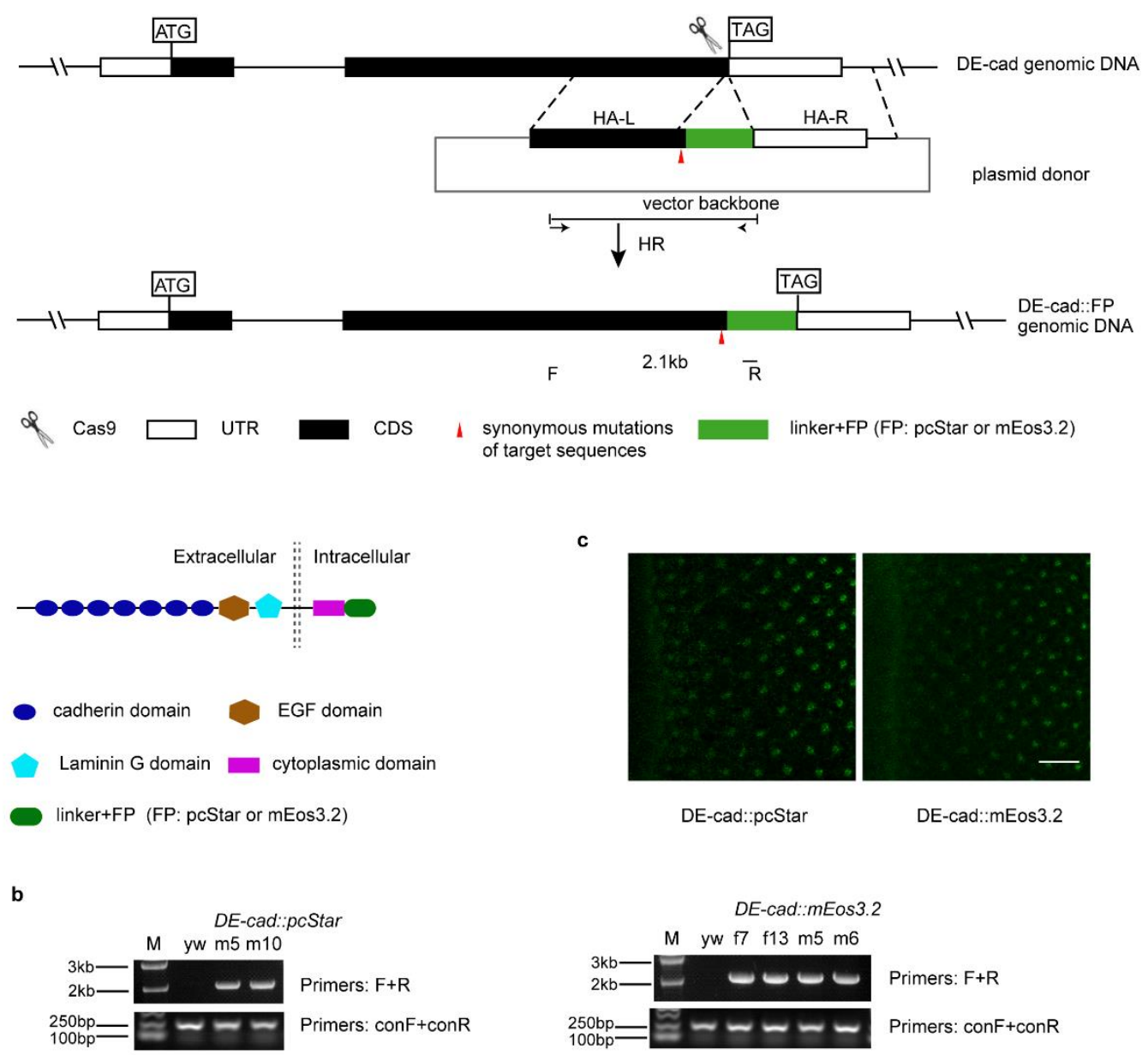

Supplementary Figure 10 Generation of endogenous DE-cad::pcStar and DEcad::mEos3.2 flies. a, Schematic of homologous recombination mediated by CRISPR/Cas9 at the $D E$-cad locus and structure of the fusion protein. b, Strain identification of the knock-in. PCR products were amplified from $\mathrm{F}_{1}$ genomic DNA of $D E$-cad::pcStar (left) and DE-cad::mEos3.2 (right). In each, the primer position and size of the PCR product in the upper panel are shown in a; the lower panel is the genomic DNA quality control, in which the PCR product was amplified by using primer pairs for another gene. M, molecular marker; $y w$, flies were used for microinjection as a negative control; the rest are different lines of $\mathrm{F}_{1}$. $\mathbf{c}$, Confocal microscopy images of eye imaginal discs from $3^{\text {rd }}$ instar larvae of $D E$-cad::pcStar (left) and $D E$-cad::mEos3.2 (right) to verify successful knock-in. A high density of DE-cad was localized at the cell-cell boundaries in ommatidial precluster cells. Anterior is towards the left and dorsal is towards the top. The arrowhead indicates the morphogenetic furrow, and the posterior part to the morphogenetic furrow is shown. Scale bar is $20 \mu \mathrm{m}$. 

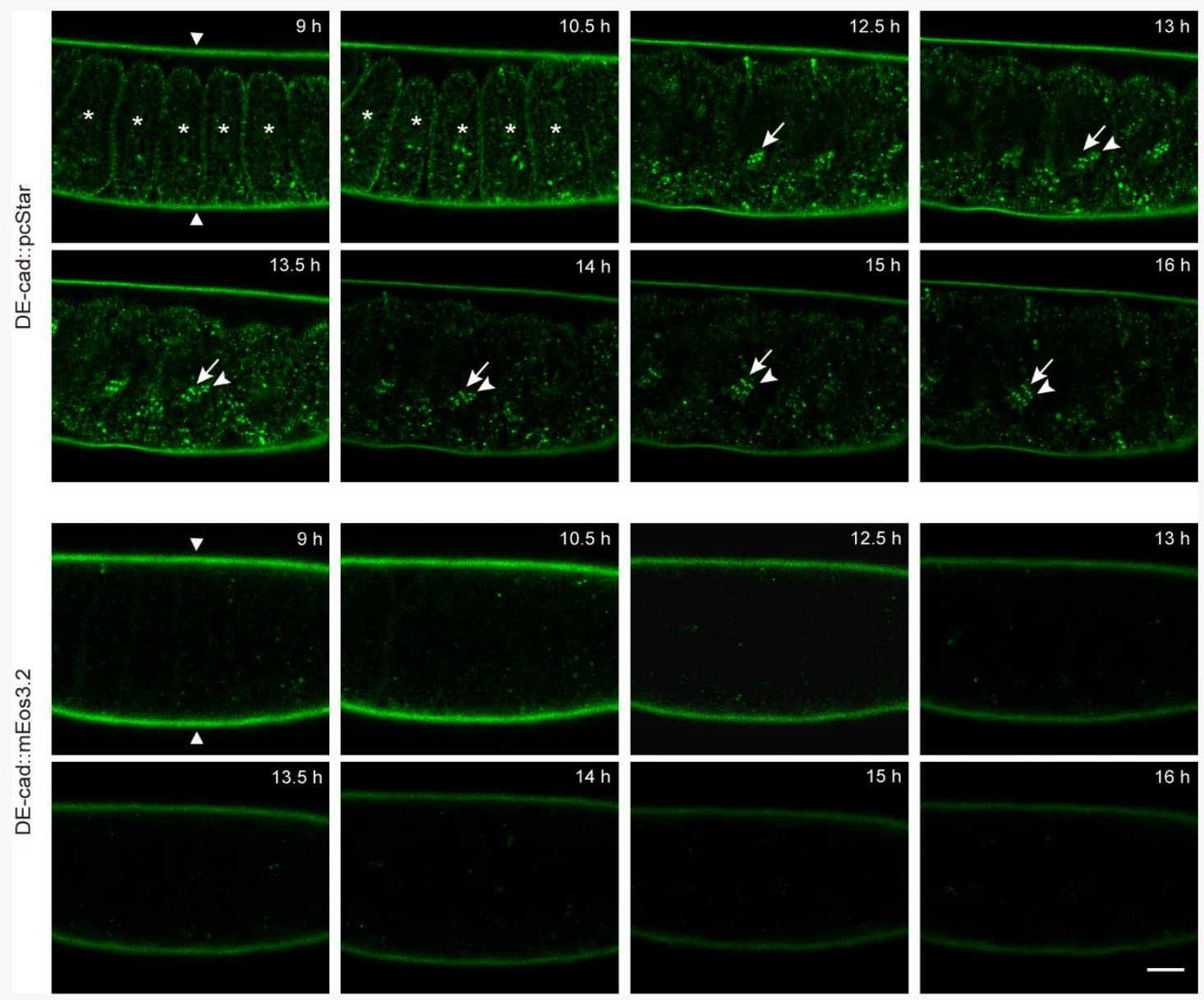

Supplementary Figure 11 Development of Drosophila embryonic Ich5 organs visualized by pcStar in vivo tagged DE-cad. Live confocal imaging of DEcad::pcStar- and DE-cad::mEos3.2- labeled embryonic lch5 organs at different developmental time points in the lateral view. Anterior is toward the left and dorsal is toward the top. The triangle denotes the vitelline membrane; the asterisk indicates a segment; the arrow and arrowhead mark primary three and the secondary two scolopidia of the lch5 organs, respectively. Each time point indicates the developmental time of the embryo after egg lay (AEL). Scale bar is $20 \mu \mathrm{m}$. 

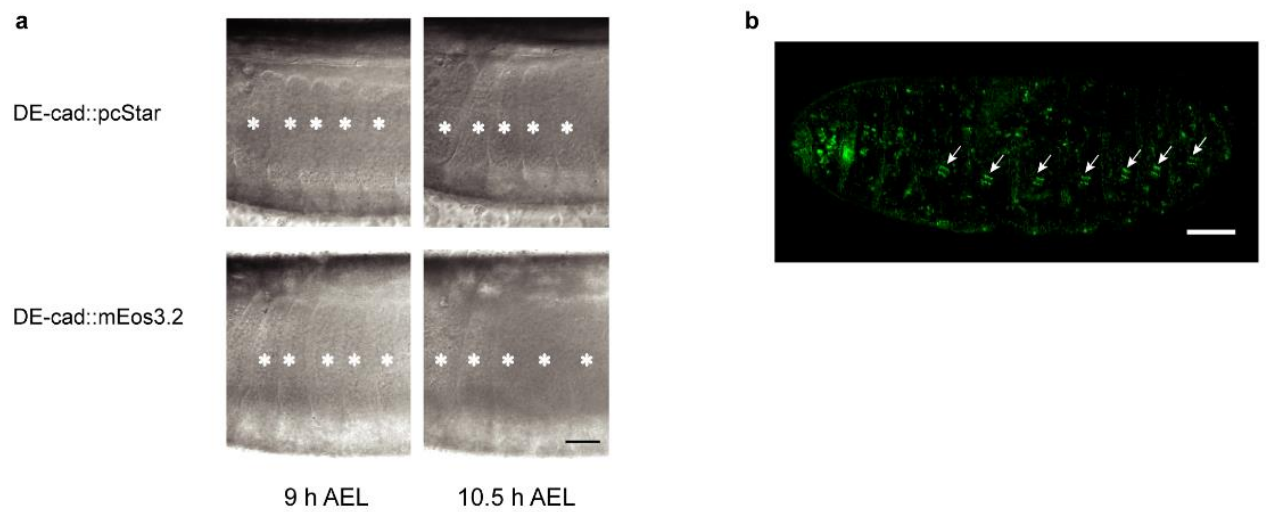

Supplementary Figure 12 Drosophila embryonic segments and the DE-cadlabeled lch5 organ. a, Bright-field images of Drosophila embryonic segments at $9 \mathrm{~h}$ AEL and $10.5 \mathrm{~h}$ AEL (lateral view). One asterisk indicates a segment. Anterior is on left, and dorsal is on the top. AEL, after egg lay. b, Lateral view of DE-cad::pcStar embryo (stage 16). pcStar labeled DE-cad displays two rows on each segment from the abdominal one to seven (A1-A7), as indicated by arrows. Anterior is towards the left and dorsal is towards the top. Scale bar: $30 \mu \mathrm{m}(\mathbf{a}), 50 \mu \mathrm{m}$ (b) 

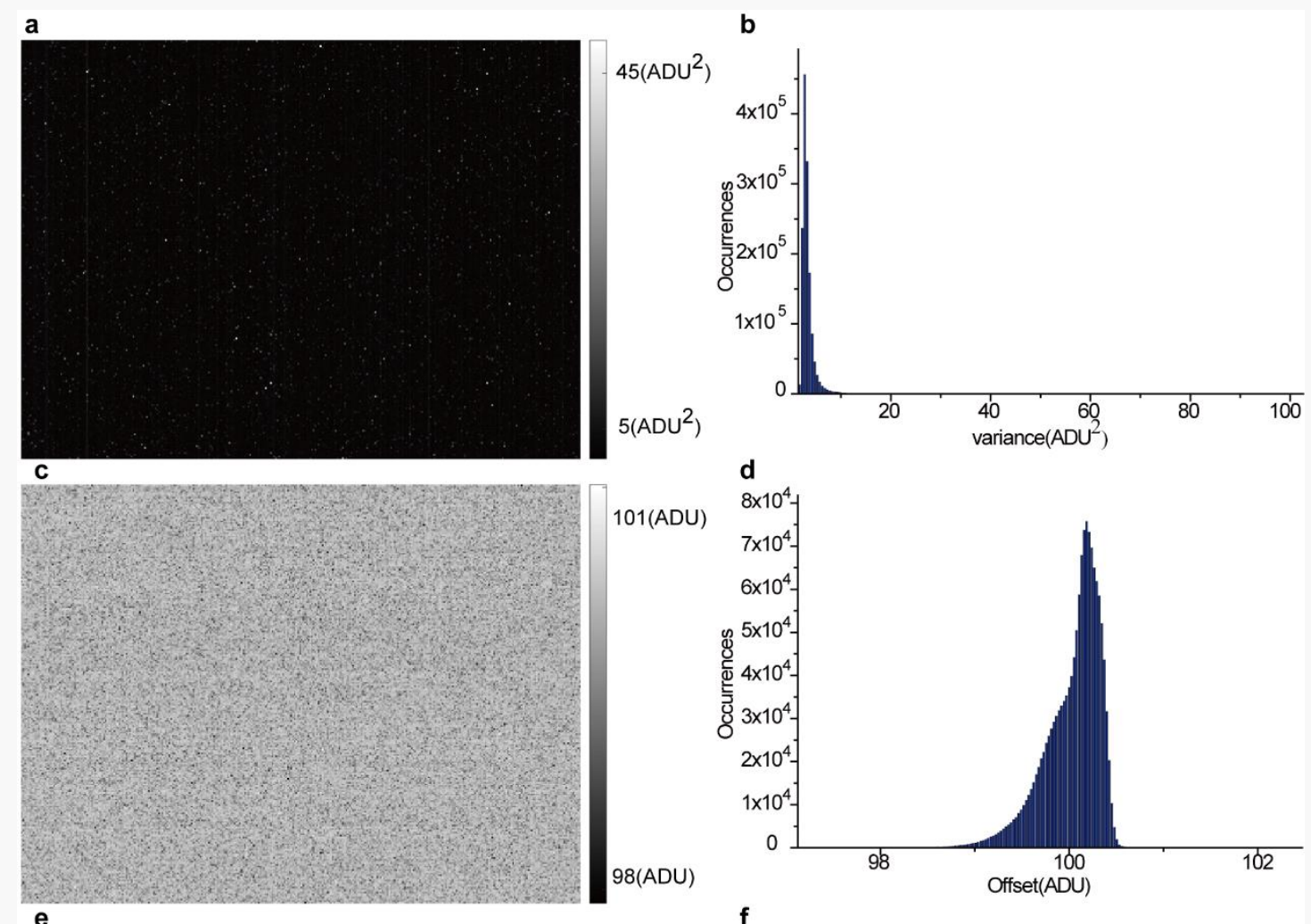

101(ADU)
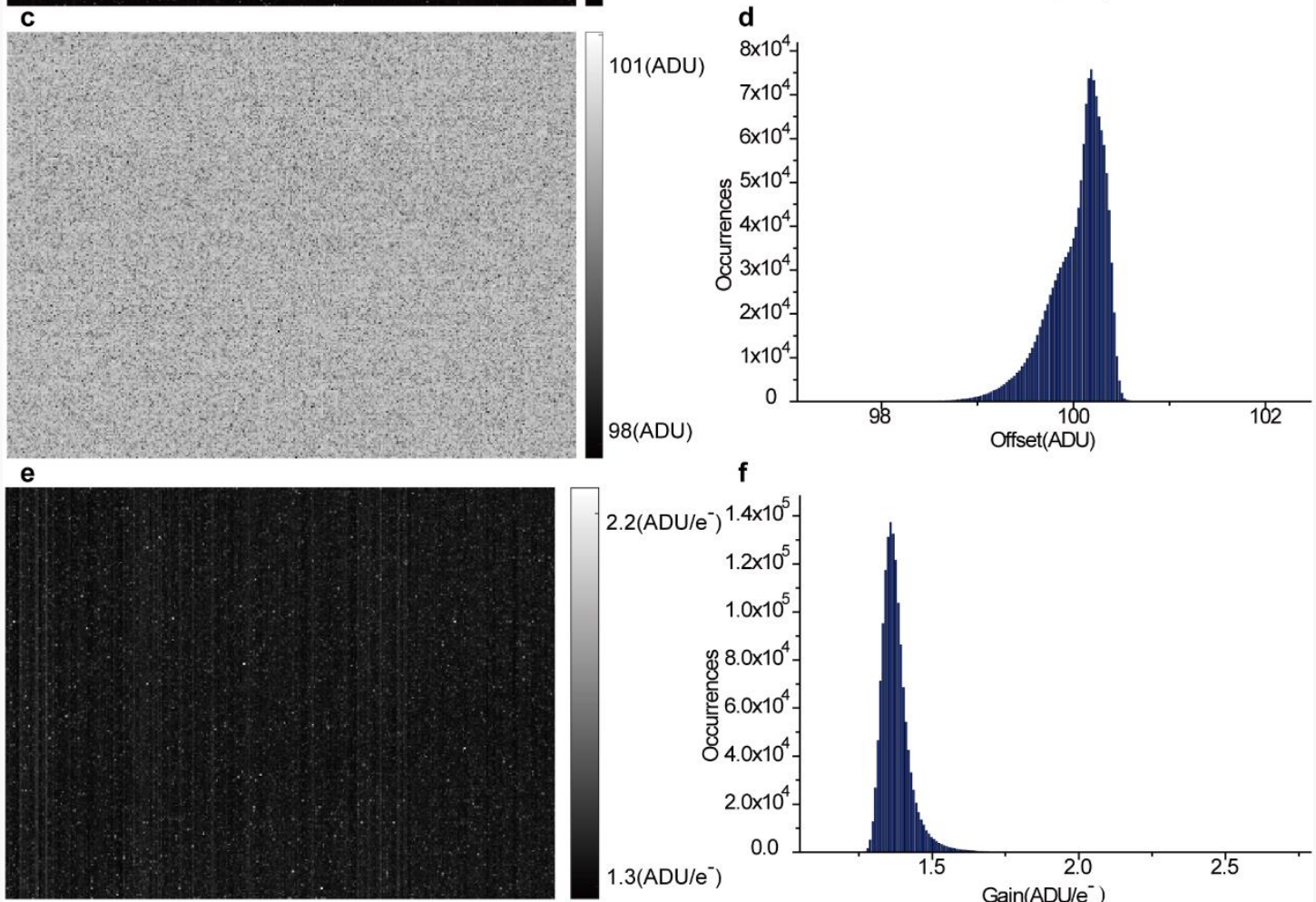

98(ADU)

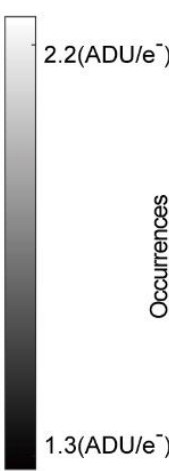

f

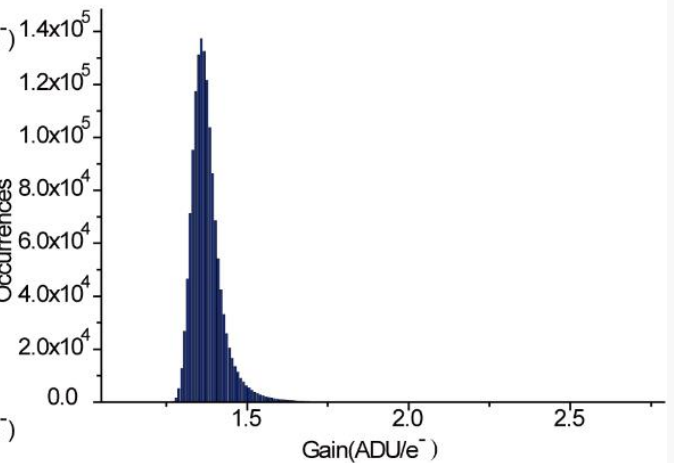

Supplementary Figure 13 Pre-characterization of pixel-dependent noise of

sCMOS camera. a, c, e, Maps shown the noise variance (a), offset (c) and gain (e) for each pixel. b, d, f, Histograms of the variance (b), offset (d) and gain (f), respectively. 
a

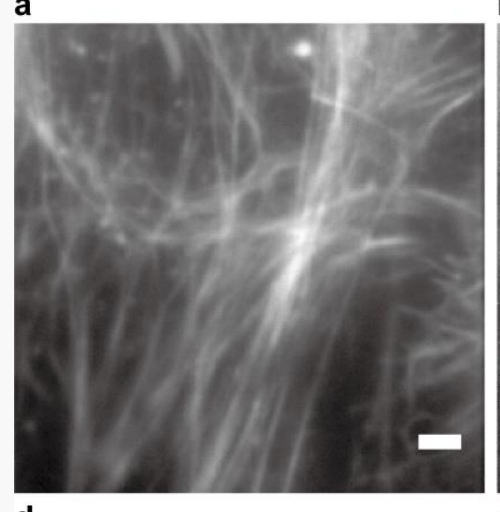

d

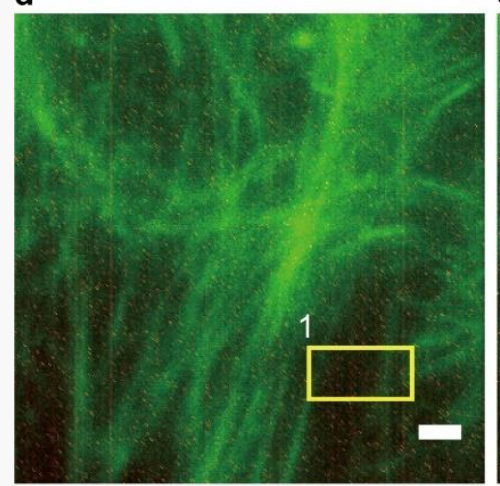

b

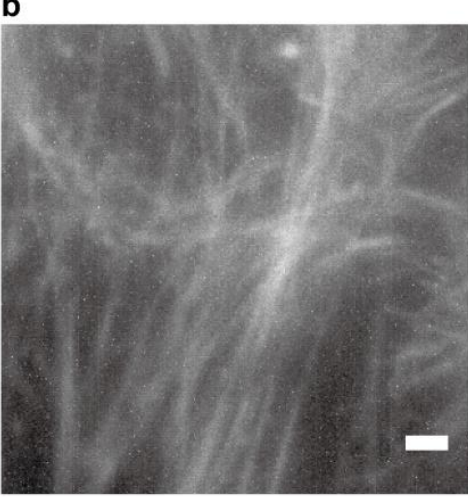

e

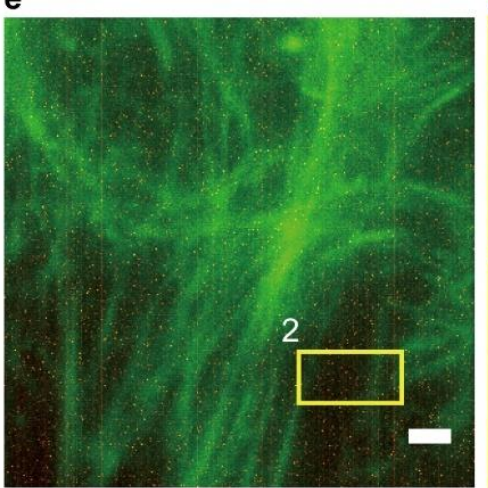

c

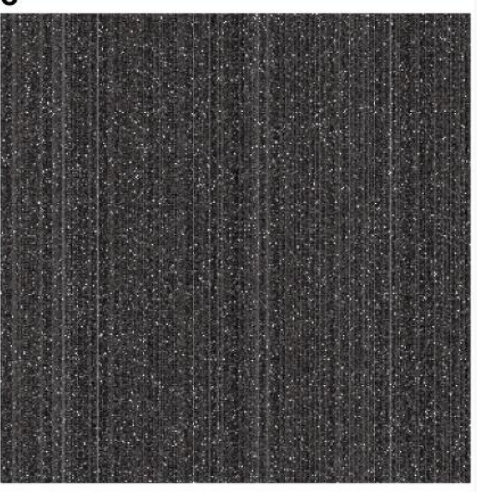

f
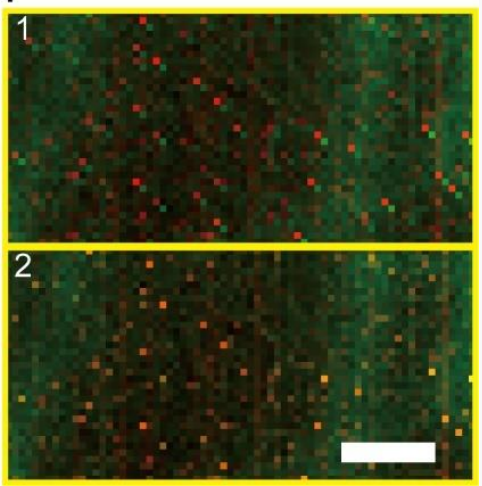

Supplementary Figure 14 Validation of sCMOS noise calibration. a, Sum of a 200 raw frames of U2OS cell expressing lifeact-pcStar. b, The variance map of the 200 raw frames. $\mathbf{c}$, The variance map of sCMOS in the corresponding FOV. d, Merge of $\mathbf{b}$ (green) and $\mathbf{c}$ (red). e, Merge of x-y shifted $\mathbf{b}$ (green) and $\mathbf{c}$ (red). f, Zoom-in of yellow box in $\mathbf{d}$ and e. Scare bars are $2 \mu \mathrm{m}$. 

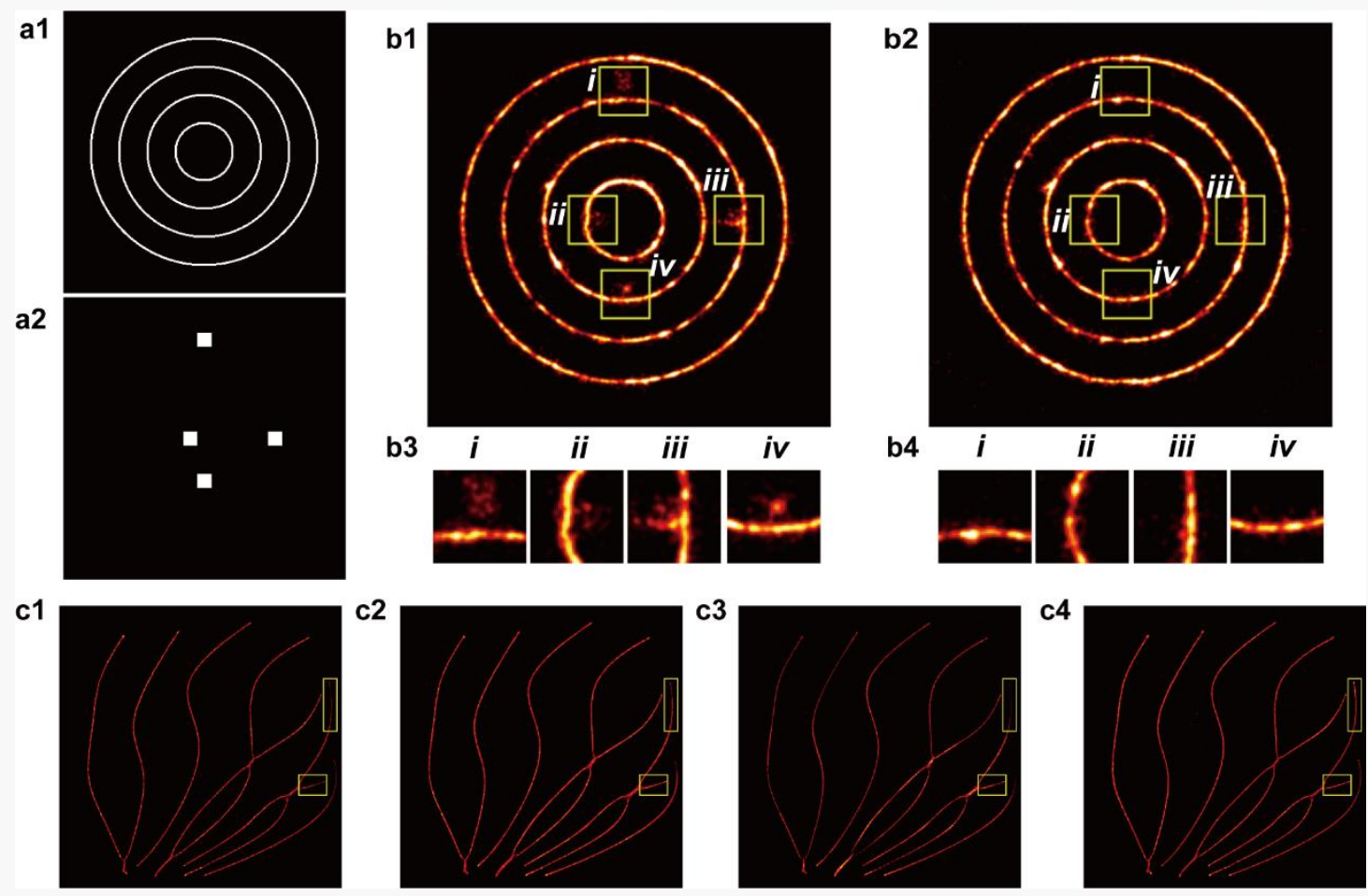

Supplementary Figure 15 Validation of sCMOS algorithm by simulation data. a, Simulation of a concentric circles image(a1) and pixel-dependent noise variance (a2). b, Reconstructed images by SIMBA algorithm without (b1) and with (b2) sCMOS noise calibration. b3 and b4, Zoom-in image of yellow box highlighted in b1 and b2 respectively. c, Comparison of reconstructed images by SIMBA and Quick-SIMBA algorithm. Images reconstructed by Quick-SIMBA algorithm without data partitioning and consolidation using 50 raw frames (c1) and 200 raw frames (c2). Images reconstructed by SIMBA algorithm using 200 raw frames (c3). Images reconstructed by Quick-SIMBA algorithm with data partitioning and consolidation using 50 raw frames (c4). 


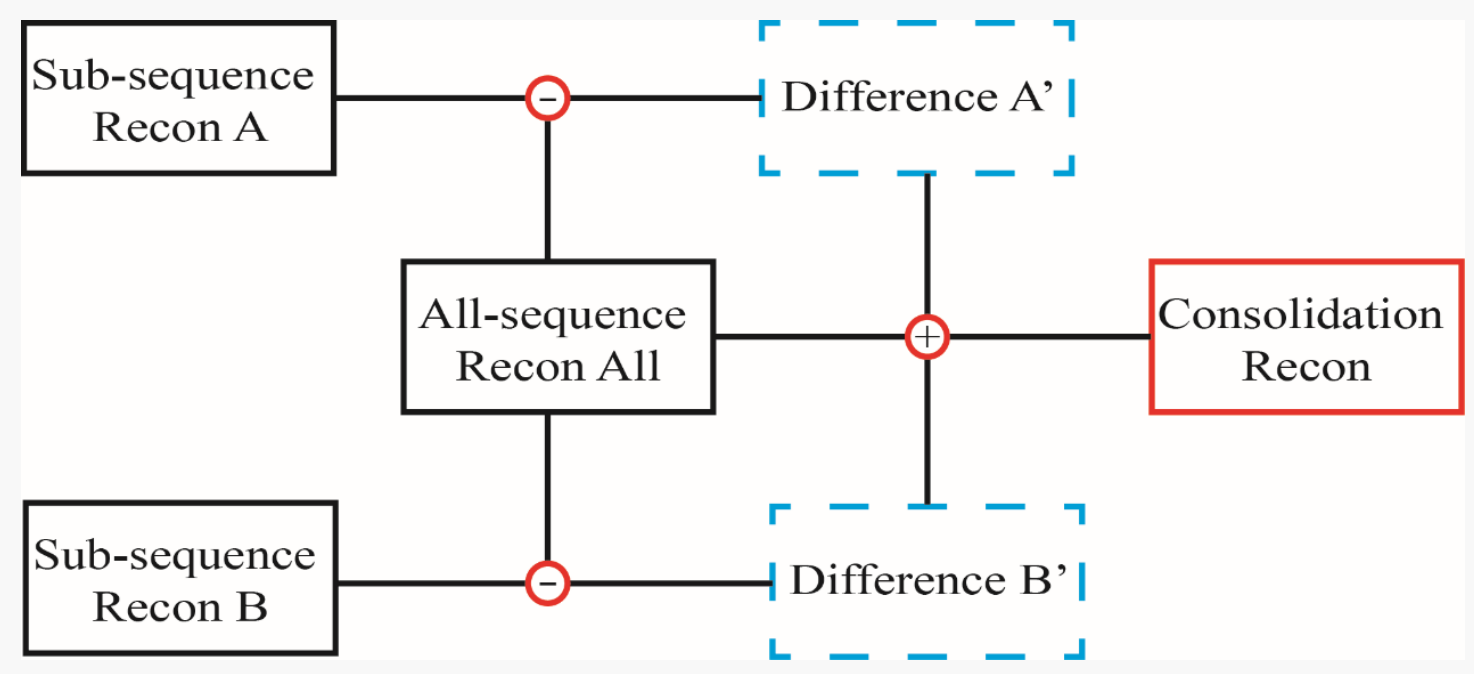

Supplementary Figure 16 Schematic diagram of data partitioning and consolidation. 
Supplementary Table 1 Statistics for the OSER assay.

\begin{tabular}{|c|c|c|}
\hline & Normal cells & Total NO. of cells \\
\hline Dendra2 & $94.0 \%$ & 277 \\
\hline mEos3.2 & $88.2 \%$ & 540 \\
\hline mMaple3 & $89.0 \%$ & 401 \\
\hline pcStar & $93.8 \%$ & 614 \\
\hline
\end{tabular}

'Normal cells' are cells with a reticular-shaped ER, without nuclear envelope (NE) thickenings, without whorl structures, and without incorrect localization. 
Supplementary Table 2 Characteristics of PCFPs.

\begin{tabular}{|c|c|c|c|c|c|c|c|c|}
\hline & $\begin{array}{c}\mathrm{EX} \\
(\mathrm{nm})\end{array}$ & $\begin{array}{l}\text { EM } \\
(\mathrm{nm})\end{array}$ & $\begin{array}{c}\mathrm{EC} \\
\left(\mathrm{M}^{-}\right. \\
\left.{ }^{1} \mathrm{~cm}^{-1}\right)\end{array}$ & QY & Brightness & $\begin{array}{l}\text { MW } \\
(\mathrm{kDa})\end{array}$ & $\begin{array}{l}\text { Oligomerization } \\
\mathrm{Kd}\end{array}$ & Ref. \\
\hline $\begin{array}{c}\mathrm{mEos} 3.2 \\
\text { (G) }\end{array}$ & 507 & 516 & 63,400 & 0.84 & 53 & \multirow{2}{*}{29.9} & \multirow{2}{*}{ I } & \multirow{2}{*}{5} \\
\hline $\begin{array}{c}\mathrm{mEos} 3.2 \\
\text { (R) }\end{array}$ & 572 & 580 & 32,200 & 0.55 & 18 & & & \\
\hline $\begin{array}{l}\text { pcStar } \\
(\mathrm{G})\end{array}$ & 505 & 515 & 74,376 & 0.89 & 66 & \multirow{2}{*}{29.6} & \multirow{2}{*}{ I } & \multirow{2}{*}{$\begin{array}{c}\text { this } \\
\text { work }\end{array}$} \\
\hline $\begin{array}{l}\text { pcStar } \\
\text { (R) }\end{array}$ & 567 & 579 & 48,403 & 0.44 & 21 & & & \\
\hline $\begin{array}{c}\text { Dendra2 } \\
(\mathrm{G})\end{array}$ & 490 & 507 & 45,000 & 0.50 & 23 & \multirow{2}{*}{29.4} & \multirow{2}{*}{ I } & \multirow{2}{*}{6} \\
\hline $\begin{array}{c}\text { Dendra2 } \\
\text { (R) }\end{array}$ & 553 & 573 & 35,000 & 0.55 & 19 & & & \\
\hline $\begin{array}{c}\text { mMaple3 } \\
\text { (G) }\end{array}$ & 489 & 506 & 15,760 & 0.37 & 5.83 & \multirow{2}{*}{30.3} & \multirow{2}{*}{ I } & \multirow{2}{*}{7,8} \\
\hline $\begin{array}{c}\text { mMaple3 } \\
\text { (R) }\end{array}$ & 566 & 583 & 23,970 & 0.52 & 12.46 & & & \\
\hline
\end{tabular}

EC: extinction coefficient; QY: quantum yield. Brightness was calculated as following: extinction coefficient $\times$ quantum yield $/ 1,000$. The molecular weight was measured by sedimentation equilibrium analytical ultracentrifugation. $\mathrm{K}_{\mathrm{d}}$ was measured by nonlinear least-squares fitting using the software package (Microcal Origin) supplied by Beckman. / represents a very high $\mathrm{K}_{\mathrm{d}}$ that was beyond the limits of our instrument. $\mathrm{G}$ : green; R: red. 
Supplementary Table 3 Statistics for photostability of PCFPs

\begin{tabular}{|c|c|c|c|c|c|c|c|c|}
\hline & $\begin{array}{l}\text { pcStar } \\
\mathrm{G}(\mathrm{s})\end{array}$ & $\begin{array}{l}\text { Dendra2 } \\
\text { G (s) }\end{array}$ & $\begin{array}{l}\text { mEos } 3.2 \\
\text { G (s) }\end{array}$ & $\begin{array}{l}\text { mMaple3 } \\
\text { G (s) }\end{array}$ & $\begin{array}{c}\text { pcStar } \\
\mathrm{R}(\mathrm{s})\end{array}$ & $\begin{array}{c}\text { Dendra2 } \\
\mathrm{R}(\mathrm{s})\end{array}$ & $\begin{array}{c}\mathrm{mEos} 3.2 \\
\mathrm{R}(\mathrm{s})\end{array}$ & $\begin{array}{c}\text { mMaple3 } \\
\text { R (s) }\end{array}$ \\
\hline $\begin{array}{c}\tau_{1 / 2} \\
(\text { mean } \\
\pm \mathrm{SD})\end{array}$ & $\begin{array}{l}102.510 \\
\pm 7.508\end{array}$ & $\begin{array}{l}101.170 \\
\pm 11.173\end{array}$ & $\begin{array}{l}99.80 \pm \\
4.806\end{array}$ & $\begin{array}{l}163.630 \\
\pm 11.753\end{array}$ & $\begin{array}{l}0.650 \pm \\
0.094\end{array}$ & $\begin{array}{l}2.600 \pm \\
0.505\end{array}$ & $\begin{array}{l}0.350 \pm \\
0.079\end{array}$ & $\begin{array}{l}2.680 \pm \\
0.866\end{array}$ \\
\hline $\mathrm{p}$ & & 0.829 & 0.516 & $\begin{array}{l}9.874 \mathrm{E}- \\
06\end{array}$ & & $\begin{array}{l}2.838 \mathrm{E}- \\
05\end{array}$ & $\begin{array}{l}5.894 \mathrm{E}- \\
04\end{array}$ & $\begin{array}{l}8.096 \mathrm{E}- \\
04\end{array}$ \\
\hline
\end{tabular}

Pair-wised two-tailed t-test assuming unequal variance was conducted between pcStar and each PCFP, $\mathrm{n}=5$. 
Supplementary Table 4 Statistics for the protein level of H2B-PCFP-SNAP fusions expressed in $\mathrm{U} 2 \mathrm{OS}$ cells at $16 \mathrm{~h}$ after transfection.

\begin{tabular}{|c|c|c|c|c|}
\hline & pcStar & Dendra2 & mEos3.2 & mMaple3 \\
\hline $\begin{array}{c}\text { Intensity ratio } \\
\text { of SNAP / }\end{array}$ & 1.678 & 1.508 & 1.260 & 1.375 \\
\cline { 2 - 5 } Actin & 1.824 & 1.680 & 1.346 & 1.302 \\
\cline { 2 - 5 } & 1.573 & 1.230 & 1.350 & 1.331 \\
\hline Mean \pm SD & $1.692 \pm 0.126$ & $1.473 \pm 0.227$ & $1.318 \pm 0.051$ & $1.336 \pm 0.037$ \\
\hline $\mathrm{P}$ & & 0.4 & 0.1 & 0.1 \\
\hline
\end{tabular}

Pair-wised Mann-Whitney U tests were conducted between pcStar and each other FP. For each FP, there are three repeats. 
Supplementary Table5 Statistics for the green fluorescent intensity of U2OS cells expressing H2B-PCFP-SNAP normalized to SNAP-Cell 647-SiR.

\begin{tabular}{|c|c|c|c|c|}
\hline & pcStar & Dendra2 & mEos3.2 & mMaple3 \\
\hline Mean \pm SD & $0.988 \pm 0.069$ & $0.479 \pm 0.040$ & $0.414 \pm 0.128$ & $0.199 \pm 0.079$ \\
\hline P & & $7.365 \mathrm{E}-11$ & $4.245 \mathrm{E}-08$ & $1.996 \mathrm{E}-13$ \\
\hline
\end{tabular}

Pair-wised two-tailed t-test assuming unequal variance was performed between pcStar and each PCFP, $n=9$. 
Supplementary Table 6 Statistics for the photoconversion contrast measurements in U2OS cells overexpressing H2B-PCFP fusions.

\begin{tabular}{|c|c|c|c|c|}
\hline & pcStar & Dendra2 & mEos3.2 & mMaple3 \\
\hline Mean \pm SD & $29.364 \pm$ & $6.313 \pm 0.811$ & $12.246 \pm$ & $29.444 \pm$ \\
& 1.772 & & 1.765 & 1.954 \\
\hline P & & $2.300 \mathrm{E}-05$ & $2.200 \mathrm{E}-05$ & 0.960 \\
\hline
\end{tabular}

Pair-wised two-tailed t-test assuming unequal variance was conducted between pcStar and each PCFP, $n=4$. 
Supplementary Table 7 Statistics for the signaling efficiency (red channel) comparison in bacteria endogenously expressing HU-PCFP fusions.

\begin{tabular}{|c|c|c|c|c|c|c|}
\hline & $\begin{array}{c}\text { No. of } \\
\text { localizations } \\
\text { per cell } \\
\text { (mean } \pm \text { SD) }\end{array}$ & $\mathrm{p}^{\#}$ & $\begin{array}{c}\text { Blinking } \\
\text { number } \\
\text { per } \\
\text { molecule } \\
\text { (mean) }\end{array}$ & $\begin{array}{c}\text { No. of } \\
\text { molecules } \\
\text { per cell* } \\
\text { (mean } \pm \text { SD) }\end{array}$ & $\begin{array}{c}\text { Fold of } \\
\text { pcStar to } \\
\text { PCFP }\end{array}$ & $\mathrm{p}^{\#}$ \\
\hline pcStar & $\begin{array}{c}31189.417 \pm \\
5733.984\end{array}$ & 3.09 & $\begin{array}{c}10093.662 \\
\pm 1855.658\end{array}$ & & \\
\hline mEos3.2 & $\begin{array}{c}5281.447 \pm \\
1179.520\end{array}$ & $\begin{array}{c}8.819 \mathrm{E}- \\
08\end{array}$ & 3.14 & $\begin{array}{c}1681.989 \pm \\
375.643\end{array}$ & 6.00 & $8.731 \mathrm{E}-08$ \\
\hline mMaple3 & $\begin{array}{c}10288.250 \pm \\
3466.911\end{array}$ & $\begin{array}{c}6.730 \mathrm{E}- \\
08\end{array}$ & 2.21 & $\begin{array}{c}4655.317 \\
\pm 1568.738\end{array}$ & 2.17 & $1.566 \mathrm{E}-06$ \\
\hline
\end{tabular}

\# Pair-wised two-tailed t-test assuming unequal variance was conducted between pcStar and each PCFP, $n=10$.

$£$ The average number of blinking events per molecule was measured in biotinylated protein fixed on cover glass for pcStar, and literature values ${ }^{7}$ for mEos3.2 and mMaple3.

* Number of localizations divided by blinking number 
Supplementary Table 8 Statistics for the red single molecular properties of PCFPs in vitro.

\begin{tabular}{|c|c|c|c|c|}
\hline & pcStar & mEos3.2 & Dendra2 & mMaple3 \\
\hline $\begin{array}{c}\text { Photon number } \\
\text { (mean } \pm \text { SD) }\end{array}$ & $\begin{array}{c}419.649 \pm \\
34.351\end{array}$ & $\begin{array}{c}422.567 \pm \\
25.481\end{array}$ & $\begin{array}{c}264.110 \pm \\
19.804\end{array}$ & $\begin{array}{c}266.777 \pm \\
15.575\end{array}$ \\
\hline$P$ & 0.941 & $2.953 \mathrm{E}-10$ & $8.265 \mathrm{E}-10$ \\
\hline $\begin{array}{c}\text { Localization } \\
\text { precision } \\
\text { (mean } \pm \text { SD) }\end{array}$ & $12.529 \pm 0.754$ & $12.970 \pm 0.193$ & $15.901 \pm 0.449$ & $14.917 \pm 0.339$ \\
\hline $\mathrm{P}$ & & 0.193 & $4.164 \mathrm{E}-10$ & $3.56 \mathrm{E}-08$ \\
\hline
\end{tabular}

Pair-wised two-tailed t-test assuming unequal variance was conducted between pcStar and each PCFP, $n=10$. 
Supplementary Table 9 Statistics for the red single molecular properties of lifeact-pcStar overexpressed in U2OS cells.

\begin{tabular}{|c|c|c|}
\hline & pcStar & mEos 3.2 \\
\hline $\begin{array}{l}\text { Photon number } \\
(\text { mean } \pm \mathrm{SD})\end{array}$ & $317.237 \pm 17.792$ & $333.283 \pm 16.935$ \\
\hline $\mathrm{P}$ & & 0.110 \\
\hline $\begin{array}{l}\text { Localization precision } \\
\quad(\text { mean } \pm \mathrm{SD})\end{array}$ & $13.561 \pm 1.176$ & $13.581 \pm 0.482$ \\
\hline $\mathrm{P}$ & & 0.968 \\
\hline $\begin{array}{l}\text { Labeling Density } \\
\left(\times 10^{2} \mu \mathrm{m}^{-2}\right) \\
(\text { mean } \pm \mathrm{SD})\end{array}$ & $201.160 \pm 48.757$ & $142.432 \pm 38.826$ \\
\hline $\mathrm{P}$ & & 0.029 \\
\hline $\begin{array}{l}\text { Nyquist resolution } \\
\qquad(\mathrm{nm}) \\
(\text { mean } \pm \mathrm{SD})\end{array}$ & $15.500 \pm 2.348$ & $19.379 \pm 2.816$ \\
\hline $\mathrm{P}$ & & 0.016 \\
\hline $\begin{array}{c}\text { Spatial resolution } \\
(\mathrm{nm}) \\
(\text { mean } \pm \mathrm{SD}) \\
\end{array}$ & $20.646 \pm 2.095$ & $23.717 \pm 2.287$ \\
\hline $\mathrm{P}$ & & 0.023 \\
\hline
\end{tabular}

The spatial resolution was calculated as:

Spatial resolution $=\sqrt{\text { localization }_{\text {precision }}{ }^{2}+\text { Nyquist }_{\text {resolution }}{ }^{2}}$

$\mathrm{p}$ was calculated using a two-tailed t-test assuming unequal variance. $\mathrm{n}=7$. 
Supplementary Table 10 On- and off- switching rate of PCFPs

\begin{tabular}{|c|c|c|c|}
\hline PCFPs & $\begin{array}{l}\text { On-switching } \\
\text { rate, frame } \\
\quad(50 \mathrm{~ms})\end{array}$ & $\begin{array}{l}\text { Mean lifetime, } \\
\text { frame }(50 \mathrm{~ms})\end{array}$ & $\begin{array}{l}\text { Off-switching rate, } \\
\text { frame }^{-1}(50 \mathrm{~ms})\end{array}$ \\
\hline pcStar & $2.83 \times 10^{-6}$ & 0.57 & 1.75 \\
\hline $\mathrm{mEos} 3.2^{7}$ & $1.63 \times 10^{-6}$ & 0.43 & 2.33 \\
\hline Dendra $2^{7}$ & $2.28 \times 10^{-6}$ & 0.22 & 4.55 \\
\hline mMaple $3^{7}$ & $2.31 \times 10^{-7}$ & 0.16 & 6.25 \\
\hline
\end{tabular}


Supplementary Table 11 Statistics for the SSIM value of the PALM reconstruction results.

\begin{tabular}{|c|c|c|c|}
\hline Stacks Merged & $\begin{array}{c}\text { Number of } \\
\text { frames }\end{array}$ & $\begin{array}{c}\text { pcStar } \\
(\text { mean } \pm \text { SD })\end{array}$ & $\begin{array}{c}\text { mEos3.2 } \\
(\text { mean } \pm \text { SD })\end{array}$ \\
\hline Stack1 & 5,000 & $0.153 \pm 0.021$ & $0.047 \pm 0.016$ \\
\hline Stack1+2 & 10,000 & $0.283 \pm 0.032$ & $0.120 \pm 0.021$ \\
\hline Stack1+2+3 & 15,000 & $0.398 \pm 0.042$ & $0.194 \pm 0.021$ \\
\hline Stack1+2+3+4 & 20,000 & $0.504 \pm 0.031$ & $0.264 \pm 0.022$ \\
\hline Stack1+2+3+4+5 & 25,000 & $0.570 \pm 0.027$ & $0.328 \pm 0.026$ \\
\hline Stack1+2+3+4+5+6 & 30,000 & $0.608 \pm 0.025$ & $0.377 \pm 0.027$ \\
\hline Stack1+2+3+4+5+6+7 & 35,000 & $0.637 \pm 0.023$ & $0.421 \pm 0.032$ \\
\hline Stack1+2+3+4+5+6+7+8 & 40,000 & $0.661 \pm 0.022$ & $0.457 \pm 0.035$ \\
\hline Stack1+2+3+4+5+6+7+8+9 & 45,000 & $0.680 \pm 0.020$ & $0.487 \pm 0.039$ \\
\hline Stack1+2+3+4+5+6+7+8+9+10 & 50,000 & $0.691 \pm 0.021$ & $0.520 \pm 0.044$ \\
\hline
\end{tabular}

SSIM values of PALM images reconstructed from gradually increasing frames. TIRF images from the green channel were used as a reference. $n=7$. 
Supplementary Table 12 Statistics for the $\tau$ 1/e of the SSIM curve of the PALM reconstruction results.

\begin{tabular}{|c|l|l|l|l|l|l|l|c|c|}
\hline & Cell1 & Cell2 & Cell3 & Cell4 & Cell5 & Cell6 & Cell7 & $\begin{array}{c}\text { Mean } \pm \\
\text { SD }\end{array}$ & $p$ \\
\hline pcStar & 3.191 & 2.963 & 2.611 & 3.334 & 3.843 & 2.906 & 5.361 & $\begin{array}{c}3.458 \pm \\
0.924\end{array}$ & \\
\hline $\begin{array}{c}\text { mEos3. } \\
2\end{array}$ & 7.212 & 8.342 & 6.954 & 7.981 & 9.209 & 6.257 & 8.979 & $\begin{array}{c}7.848 \pm \\
1.090\end{array}$ & $\begin{array}{c}4.090 \mathrm{E}- \\
06\end{array}$ \\
\hline
\end{tabular}

SSIM values of PALM images reconstructed with different stack numbers were fitted to the first order exponential function for each cell, and $\tau_{1 / \mathrm{e}}$ are listed in the table. $p$ was calculated using a two-tailed t-test assuming unequal variance. $\mathrm{n}=7$. 
Supplementary Table 13 Parameters used in the data analysis of sedimentation equilibrium experiments.

\begin{tabular}{|c|c|c|c|}
\hline PCFP & Solvent density & Partial specific volume & $\begin{array}{c}\text { Molecular weight } \\
\text { (Da) }\end{array}$ \\
\hline pcStar & 1.0056 & 0.7238 & $29,848.6$ \\
\hline Dendra2 & 1.0056 & 0.7273 & $30,254.2$ \\
\hline mEos3.2 & 1.0056 & 0.7228 & $29,873.7$ \\
\hline mMaple3 & 1.0056 & 0.7282 & $31,337.6$ \\
\hline
\end{tabular}




\section{Supplementary Note1: Detailed experimental methods}

\section{Ethics statement}

Mice were housed in isolators under pathogen-free conditions with humane care and were anaesthetized with sodium pentobarbital to minimize suffering. All experiments were approved by the ethics committee of the Institute of Biophysics (SYXK2017-41).

Development of pcStar. pcStar was generated by site-directed mutagenesis based on pRSETa-mEos3.2 using the polymerase incomplete primer extension (PIPE) method. Mutation sites were chosen anticipating an increased photoconversion contrast and added to the template stepwise. All of the intermediate mutants were sequenced, purified, and transformed into E. coli BL21(DE3)pLysS. Further analyses were performed under a wide-field upright fluorescence microscope body (Olympus MVX10) equipped with X-cite $120 \mathrm{Q}$ (halogen lamp) and a proper filter set. In addition to mEos3.2, mMaple3 and Dendra2 were also used as controls. The final mutant, which had the best comprehensive strength, including high brightness, high photoconversion contrast and early detectable fluorescence, was named pcStar.

General plasmid construction. The cDNA of mMaple3 (a gift from Prof. Yujie Sun of Peking University) and Dendra2 (Clontech Laboratories, Inc.) were PCR-amplified and cloned into the pRSETa (Clontech) vector with BamHI and EcoRI to generate pRSETa-mMaple3 and pRSETa-Dendra2. For mammalian cell expression: pLifeact/pCaveolin/pH2B-Skylan-NS ${ }^{9}$ was digested by BamHI and NotI, and SkylanNS was replaced by pcStar to construct lifeact/Caveolin/H2B/-pcStar fusions; pcStar was PCR-amplified and used to replace Skylan-NS in pSkylan-NS-MAP4 ${ }^{9}$ with AgeI and BglII to construct pcStar-MAP4; to label mitochondria with pcStar, the genes encoding pcStar were PCR-amplified and swapped with the mEos3.2 gene in the vector of pmEos3.2-Mito using AgeI and NotI; to generate pH2B-pcStar-SNAP, the cDNA of H2B, pcStar and SNAP-tag were inserted into the vector of pEGFP-N1 between NheI and XhoI, HindIII and SalI, and AgeI and NotI, respectively; to generate pcStarCalnexin, the cDNA of pcStar was digested with Age I and Not I and swapped with 
mPA-GFP in the mPA-GFP-Calnexin plasmid (Addgene \#57122). For the OSER assay, the cDNA of CytERM was synthesized (Generay Biotech Co., Ltd) and inserted into the vector of pEGFP-N1 between BglII and EcoRI, and then pCytERM-EGFP was digested with AgeI and NotI to replace EGFP with pcStar, Dendra2, mEos3.2 or mMaple3. Synthetic DNA primers for cloning and site-specific random mutations were purchased from Invitrogen. All plasmids were sequenced (Invitrogen) before further analysis. The restriction enzymes were purchased from Thermo Fisher Scientific.

Fly stocks. $y w$ was used for micro-injection. The $2^{\text {nd }}$ chromosome Balancer $y w$; $B c G / C y O$ was used to balance knock in flies. The $D E-c a d$ null mutant $D E-C a d^{G X 6 w-} / C y O^{10}$ was a gift from Dr. Juan Huang at Nanjing Medical University.

Generation of DE::pcStar and DE::mEos3.2 flies DE::pcStar and DE::mEos3.2 flies were generated by homologous recombination mediated by CRISPR/Cas9 according to the methods of Yu. et al. ${ }^{11}$. The gRNA targets CCGACATGTACGGCGAGGAG, which is $68 \mathrm{bp}$ upstream of the stop codon. The left homologue arm (HA-L) and right homologue arm (HA-R) were amplified by PCR using $y w$ genomic DNA as a template and cloned into the pBlueScript $\mathrm{KS}$ vector together with a PCR fragment (inF) containing sequences from the targeted sequence to the end of the CDS, linker sequences and sequences of pcStar or mEos3.2 to obtain donor plasmid. Primer pairs for HA-L and HA-R were as follows: HA-L forward, CCGCTCGAG CAATACGTCGGTATCCAACGTGG; HA-L revers, CCGGCTGCCTCCGATGCGCCAGCCCTGGTCATC; HA-R forward, CCGGAATTCTAGGAATCTTCGCCAGCCGC; HA-R reverse, GGTGGCGGCCGCCCAAAGgCAGgCGTAACCTAC. Primers for inF were as follows: inF forward, TGGCGCATCGGAGGC AGCAGTGCGATTAAGCCAGACG; inF reverse, GGCTGGCGAAGATTCCTATCGTCTGGCATTGTCAGG. Donor plasmid together with in vitro transcribed gRNA and Cas9 mRNA were co-injected into 
$y w$ embryos $\left(\mathrm{F}_{0}\right)$. Eclosed $\mathrm{F}_{0}$ were crossed with Balancer flies to generate $\mathrm{F}_{1} . \mathrm{F}_{1}$ were screened to identify knock-in positive flies by PCR, sequencing and imaging.

Mammalian cell culture and transfection. U2OS cells were cultured in McCoy's 5A Medium (MCMM) (Gibco) supplemented with 10\% (vol/vol) FBS and maintained at $37{ }^{\circ} \mathrm{C}$ and $5 \%$ (vol/vol) $\mathrm{CO}_{2}$ in a humidified incubator. COS-7 cells were cultured in Dulbecco's Modified Eagle Medium (DMEM) supplemented with glucose (Gibco), 10\% foetal bovine serum (Life Technologies) and penicillin/streptomycin (HyClone). Cells were then transiently transfected using Lipofectamine 2000 (Invitrogen) in accordance with the manufacturer's protocol. Four hours after transfection, the cells were trypsinized and plated at a lower density on clean coverslips (Fisher Scientific) coated with $10 \mathrm{mg} / \mathrm{ml}$ fibronection (Millipore, FC010) to induce spreading for another $24 \mathrm{~h}$. The cells were fixed with prewarmed fixative solution (4\% paraformaldehyde and $0.2 \%$ glutaraldehyde in PBS) for $15 \mathrm{~min}$ at $37^{\circ} \mathrm{C}$, washed three times with PBS, and stored in PBS until fixed cell imaging. For live cell imaging, culture medium was replaced with phenol red-free DMEM (Gibco). For drift calibration, $1 \mu$ l TetraSpeck Microspheres (Invitrogen) and $500 \mu \mathrm{l}$ medium or buffer were well mixed and added into the sample chamber just before usage.

Protein expression and purification. Proteins of pcStar, Dendra2, mEos 3.2 and mMaple3 were expressed in E. coli BL21(DE3)pLysS and purified using a Ni-NTA His-Bind resin (Qiagen) followed by a gel-filtration step using a Superdex 200 Increase 10/300 GL column (GE Healthcare). For additional analysis, purified proteins were concentrated by ultrafiltration and diluted in PBS to the proper concentration indicated in each experiment.

Measurement of Spectral Properties and pKa. The proteins were first diluted in 0.1 M PBS to limit UV-light absorption to less than 0.1 such that the quantum yields could be accurately measured. The absorption, excitation and emission spectra were then immediately recorded using an Agilent $8453 \mathrm{UV}$-visible spectrophotometer and an 
Edinburgh Instrument FLS920, respectively. For the emission spectra, pcStar was irradiated with $465 \mathrm{~nm}$ (530 nm for the red form) light. To determine the fluorescence excitation spectra, fluorescence was recorded at $512 \mathrm{~nm}(600 \mathrm{~nm}$ for the red form). Fluorescence quantum yields and molar extinction coefficients at the respective absorption maxima of the green form were determined relative to the reported value for Dronpa (quantum yield, 0.68; molar extinction coefficient at $503 \mathrm{~nm}, 125000 \mathrm{M}^{-1}$ $\left.\mathrm{cm}^{-1}\right)^{12}$ For red-form fluorescence, rhodamine (quantum yield, 0.65) in alcohol was used as the reference for calculating quantum yields at $550 \mathrm{~nm}$, and the molar extinction coefficients at $570 \mathrm{~nm}$ were determined by comparison between the absorbance decrease in the green forms and increase in the red forms, as previously described ${ }^{13,14}$. pKa data were obtained in a Varioskan Flash spectral scanning multimode reader (Thermo Scientific) with 96-well optical bottom plates (Nunc). Purified pcStar was diluted in buffers with various $\mathrm{pH}$ values ranging from 3 to 11; the emission fluorescence at $518 \mathrm{~nm}(590 \mathrm{~nm}$ for the red form) was immediately recorded. Data points were fitted by the dose-response function (Origin) according to Equation 5. The $\mathrm{pKa}$ value was considered the $\mathrm{pH}$ value at which the fluorescence reached $50 \%$ of the maximum.

$y=A_{1}+\frac{A_{2}-A_{1}}{1+10^{(\log x 0-x) p}} \quad($ Equation 5)

Maturation kinetics measurements in vitro. One microliter of the protein sample (6.5 $\mathrm{mg} / \mathrm{ml}$ ) of each PCFP was diluted in $400 \mu \mathrm{l}$ denaturation solution (8 M urea, $1 \mathrm{mM}$ DTT) and heated to $95^{\circ} \mathrm{C}$ for $5 \mathrm{~min}$. After the samples were cooled to $25^{\circ} \mathrm{C}$, refolding reactions were initiated upon 20 -fold dilution into the renaturation buffer $(35 \mathrm{mM} \mathrm{KCl}$, $2 \mathrm{mM} \mathrm{MgCl} 2,50 \mathrm{mM}$ Tris $\mathrm{pH} 7.5,1 \mathrm{mM}$ DTT). Protein maturation was assessed by monitoring the recovery of fluorescence at $525 \mathrm{~nm}$ using a SpectraMax M3 Multi-Mode Microplate Reader (Molecular Devices) at $37^{\circ} \mathrm{C}$. For each sample, 4 replicates were recorded every $0.5 \mathrm{~min}$ for the first half hour and then every 2 min until the end of the assessment for a total time of $5 \mathrm{~h}$. For each replicate, the kinetics data were computerfitted to the second order exponential decay (Origin) using Equation 6 or the third 
order exponential decay (Origin) using Equation 7 when the second order failed. The final maturation time $\tau_{1 / \mathrm{e}}$ at which the fraction of mature protein reached a value of $1 / \mathrm{e}$ was determined by averaging the $\mathrm{t} 1$ value from the 4 replicates.

$y(x)=y_{0}+A_{1} e^{-\frac{x}{t 1}}+A_{2} e^{-\frac{x}{t 2}}$

$y(x)=y_{0}+A_{1} e^{-\frac{x}{t 1}}+A_{2} e^{-\frac{x}{t 2}}+A_{3} e^{-\frac{x}{t 3}}$
(Equation 6)

(Equation 7)

Analysis of oligomerization. Size-exclusion chromatography was performed using a Superdex 200 Increase 10/300 GL column and an Akta purifier system (GE Healthcare) at $16{ }^{\circ} \mathrm{C}$. Proteins were concentrated to $10 \mu \mathrm{M}$. Protein absorption at $280 \mathrm{~nm}$ was monitored. Sedimentation equilibrium experiments were performed on a Beckman Optima XL-I analytical ultracentrifuge at $20{ }^{\circ} \mathrm{C}$ as previously described. Purified proteins at 8 to $20 \mu \mathrm{M}$ were loaded into 6-channel centrifugation cells and normalized to the corresponding dialysis buffer (PBS $\mathrm{pH}$ 7.4). The samples were centrifuged at 18,000 r.p.m. The data were analysed by nonlinear least-squares analysis using the software package (Microcal Origin) supplied by Beckman. The solvent density, partial specific volume and calculated molecular weight used in the analysis were determined by Sedenterp v 1.01 and listed in Table S13. Sedimentation velocity experiments were performed using purified protein at $50 \mu \mathrm{M}$ loaded into centrifugation cells and normalized to the corresponding buffer (PBS, pH 7.4). For the OSER assay, PCFPs were fused to the cytoplasmic end of an endoplasmic reticulum (ER) signal-anchor membrane protein (CytERM) and expressed in cells. At $24 \mathrm{~h}$ after transfection, images were acquired by FV1200 confocal microscopy. Representative images of "normal ER" and "ER whorl" from the literature were used as controls._Hundreds of cells were analysed for each FP, and the percentage of cells that have a normal reticular-shaped ER, without nuclear envelope (NE) thickenings, without whorl structures, and without incorrect localization, was counted and summarized in Table S1.

Blinking Characterization. To characterize blinking in vitro, purified pcStar proteins were incubated with EZ-Link ${ }^{\mathrm{TM}}$ NHS-PEG4-Biotin (Thermo Scientific) in PBS buffer 
for approximately $30 \mathrm{~min}$; then, unbound molecules were removed by PD-10 Desalting Columns (GE healthcare). To keep fluorescence proteins immobilized, cleaned cover glasses were treated with $5 \mu \mathrm{l}$ of $1 \mathrm{mg} / \mathrm{ml}$ biotin-BSA and $5 \mu \mathrm{l}$ of $1 \mathrm{mg} / \mathrm{ml}$ streptavidin sequentially for $5 \mathrm{~min}$. The cover glasses were then washed twice, and $10 \mu 1$ of 0.01 $\mu \mathrm{M}$ biotinylated pcStar were incubated on cover glasses. Finally, the cover glasses were placed in PBS buffer. Single molecules were imaged using a $561 \mathrm{~nm}$ laser for 5,000 frames (exposure time: $50 \mathrm{~ms}$ ). The numbers of blinking events were extracted with custom-written programs.

Photostability measurement. Cultured $\mathrm{CHO}$ cells expressing H2B-PCFP-SNAP fusions were fixed after $36 \mathrm{~h}$ of transfection with $4 \%$ PFA and $0.2 \%$ glutaraldehyde in PBS at $4{ }^{\circ} \mathrm{C}$ for $15 \mathrm{~min} .1,000$ sequential images were taken on a wide field fluorescence microscope with an Olympus IX71 body (Olympus), a 100×, 1.49 NA oil objective (Olympus PLAN APO) and an electron-multiplying charge-coupled device (EMCCD) camera (Andor iXon DV-897 BV). The power intensity near the focus of the objective was $3 \mathrm{~W} / \mathrm{cm}^{2}$ for the $488-\mathrm{nm}$ laser (Coherent) and $300 \mathrm{~W} / \mathrm{cm}^{2}$ for the $561-\mathrm{nm}$ laser (Coherent). The exposure time was $50 \mathrm{~ms}$.

Signalling efficiency of PCFPs in live bacteria. PCFPs were inserted into the $E$. coli BW25993 chromosome and fused to the C-terminus of the nucleoid-associated protein subunit HupA by Lambda Red Recombination ${ }^{15}$. First, pcStar and mEos3.2 were amplified and replaced with mMaple3 in pSCS3V31C-mMaple3 (a gift from Prof. Yujie Sun of Peking University), in which mMaple3 was inserted between BamHI and XbaI to replace the stop cassette of the selection-counter-selection template plasmid pSCS3V31C ${ }^{16}$. Second, the linker-PCFP-Toxin-CmR fragment was amplified from the pSCS3V31C-PCFP with a homologous arm complementary to the flanking sequences of the insertion site on the chromosome. Then, the PCR fragments were transformed into competent cells with an induced recombineering helper plasmid (pSIM6) by electroporation. After $5 \mathrm{~h}$ of recovery, the transformed cells were plated on selection plates containing chloramphenicol. Finally, positive clones were screened by PCR 
verification followed by DNA sequencing. To characterize the signalling efficiency of PCFPs in bacteria, E. coli strains expressing the HU-PCFP fusions were inoculated into $1 \mathrm{ml} \mathrm{LB}$ and grown to saturation overnight while shaking at $37^{\circ} \mathrm{C}$. The cultures were amplified 1:100 into $1 \mathrm{ml} \mathrm{M9}$ medium (with 0.4\% glucose, without vitamins), harvested when the OD 600 reached 0.4-0.6 and washed twice with filtered PBS. The strains were then fixed with $4 \%$ paraformaldehyde for $15 \mathrm{~min}$ and washed another 3 times with PBS to remove extra PFA. The washed cells were then placed on poly-lysine coated cover slides and examined by PALM imaging.

Sample preparation for single molecule property measurements in vitro. Thirty microliters of purified proteins $(1.25 \mu \mathrm{g} / \mathrm{ml})$ were dispersed on a glass slide pretreated with glow discharge. Then, a round cover glass was slowly flipped on top of the glass slide. The sample was placed at room temperature for $5 \mathrm{~min}$ and sealed with nail polish.

In utero intraventricular injection and electroporation. The protocol used has been described previously (https://www.ncbi.nlm.nih.gov/pubmed/18997887). Briefly, pregnant ICR mice (E13) from Beijing Vital River Laboratory Animal Technology were anaesthetized with sodium pentobarbital at $30 \mathrm{mg} / \mathrm{kg}$ of body weight. Plasmid DNA solution $(2.5 \mu \mathrm{g} / \mu \mathrm{l})$ containing $0.01 \%$ Fast Green was injected $(2 \mu \mathrm{l})$ into the right side of the lateral ventricle with glass micropipettes (Drummond Scientific, \#5-0001001-X10). The heads of embryos in the uterus were placed between the Tweezertrode Electrode (7 mm in diameter, BTX Harvard Apparatus), and five electrical pulses (39 $\mathrm{V}$ for $50 \mathrm{~ms}$ in duration at intervals of $950 \mathrm{~ms}$ ) were delivered using an electroporator (ECM830, Harvard Apparatus). Then, the peritoneal cavity was lavaged with $10 \mathrm{ml}$ warm PBS ( $\mathrm{pH} 7.4$ ) containing antibiotics. The uterine horns were replaced, and the wound was closed.

Brain sectioning and immunohistochemistry. Mouse embryos were dissected at 12 $\mathrm{h}$ after injection. Brains were fixed in $4 \%$ paraformaldehyde and $0.2 \%$ glutaraldehyde in $0.1 \mathrm{M}$ PBS overnight and dehydrated in $30 \%$ sucrose for $24 \mathrm{~h}$. After dehydration, the 
brains were embedded in OCT (Leica) and sectioned on a Cryostat (Leica, CM1900). Slices were stained with Hoechst 33258 for $15 \mathrm{~min}$ and washed three times with $0.1 \mathrm{M}$ $\mathrm{PBS}^{17}$.

Preparation of Drosophila sample for imaging. Time lapse confocal imaging of living embryos: embryos were collected 15 min after egg lay (AEL) and dechorionated by $\mathrm{NaClO}$ for $40 \mathrm{~s}$ followed by wash, arrangement and fixed on a cover slide. The embryos were covered with Halocarbon oil 700 (Sigma-Aldrich, H8898) after desiccation. The embryos were maintained at $25{ }^{\circ} \mathrm{C}$ with $60 \%$ moisture for development. Preparation of eye imaginal disc for confocal microscopy: eye imaginal discs from 3rd instar larvae were dissected and fixed with $4 \%$ paraformaldehyde. The discs were washed four times with PBS, mounted on a slide and covered with a cover slide. Super resolution imaging: embryos were prepared as described for confocal microscopy except they were placed on a slide instead of a cover slide. The embryos were maintained at $25{ }^{\circ} \mathrm{C}$ and $60 \%$ moisture for development and then anaesthetized with $\mathrm{CO}_{2}$ at designated time points and covered with a cover slide.

Confocal microscopy and imaging. Confocal imaging was performed using an FV1200 microscope (Olympus) for the fusion property tests (Figure 1g), photoconversion contrast measurements (Figure 3a), the OSER assay (Figure S3), time-lapse imaging of living Drosophila embryos (Figure S11) and fixed Drosophila eye imaginal disc (Figure S10c). All the abovementioned figures were produced using a 100×, 1.4 numerical aperture (NA) oil-immersion objective except Figure S11, in which a $60 \times, 1.4$ NA oil-immersion objective was used. The maximum power near the rear pupil of the objective was $0.18 \mathrm{~mW}$ for the $405-\mathrm{nm}$ laser (LASOS), $0.24 \mathrm{~mW}$ for the $488-\mathrm{nm}$ laser and $0.08 \mathrm{~mW}$ for the 561-nm laser. Data were analysed using FluoView software (Olympus) and Fiji (US National Institutes of Health). In the photoconversion contrast measurements, the sequential mode was used to record both the green and the red channels. For each channel, one image was acquired before applying the 405-nm laser, and then a series of images was acquired continuously until 
obvious photobleaching appeared in the red channel. The photoconversion contrast (PC) was calculated as shown in Equation 8.

$P C=\frac{\text { Green }_{\max }}{\text { Green }_{\min }} \quad X \frac{\text { Red }_{\max }}{\text { Red }_{\min }}$ (Equation 8)

For living Drosophila embryo imaging, sample slides were fixed in a special chamber and installed in a live cell imaging system to maintain the designated temperature and moisture during imaging. Images were obtained every $30 \mathrm{~min}$ from $8 \mathrm{~h}$ AEL to $16 \mathrm{~h}$ AEL or at the mentioned time point. The Z-axis was scanned. Bright-field images were simultaneously obtained based on a fluorescent signal.

Super-resolution imaging and analysis. For PALM, SIMBA and Quick-SIMBA imaging, images were acquired using a homemade TIRF microscopy system with an Olympus IX71 body (Olympus) and a 100×, 1.49 NA oil objective (Olympus PLAN APO). A 1.6x intermediate magnification was also used with an image pixel size of $100 \mathrm{~nm}$. The fluorescence signals were acquired using an electron-multiplying chargecoupled device (EMCCD) camera (Andor iXon DV-897 BV) for PALM and SIMBA. A scientific complementary metal-oxide-semiconductor (sCMOS) camera (Prime95B, Photometrics) was used for Quick-SIMBA. The maximum power intensity near the back pupil of the objective was $2.5 \mathrm{~mW} / \mathrm{cm}^{2}$ for the $405-\mathrm{nm}$ laser (LASOS), $2.5 \mathrm{~W} / \mathrm{cm}^{2}$ for the 488-nm laser (Coherent) and $1.5 \mathrm{~kW} / \mathrm{cm}^{2}$ for the $561-\mathrm{nm}$ laser (Coherent). For PALM imaging, a 561-nm laser was used to record single molecules, while a 405-nm laser pulse was simultaneously used to activate the FPs. The intensity of the 405-nm laser was set low so that it only activated a few molecules in each frame. PALM analysis was performed using custom routines in MATLAB as described previously ${ }^{5}$.

SIMBA imaging was conducted as previously described ${ }^{18}$. Briefly, a continuous 488 $\mathrm{nm}$ laser was used for the Bayesian calculation, while a continuous 561-nm laser and a pulse 405-nm laser were used for single molecule localization. Then, 1,000 sequential frames were acquired with an exposure time of $50 \mathrm{~ms}$. Reconstructed images were generated using the SIMBA algorithm as previously described ${ }^{18}$. For Bayesian analysis, 
the choice of priors and Markov chain Monte Carlo settings were the same as before ${ }^{18}$. Other analysed data were generated using Origin and ImageJ software.

For Quick-SIMBA, a 405-nm pulse, a 488-nm and a 561-nm continuous laser were simultaneously used to record the green channel signal for Bayesian calculation and the red channel signal for single molecule position extraction. For Quick-SIMBA of fixed actin, 50 sequential frames were acquired with an exposure time of $2 \mathrm{~ms}$ for each frame (FOV: $764 \times 94$ pixels) and 5 ms (FOV: $680 \times 320$ pixels). For Quick-SIMBA of live actin, 2,500 image frames with a 5-ms (FOV: $806 \times 430$ pixels) exposure time were performed. Every other 50 frames (i.e., a SIMBA image at one time point), a $20 \mathrm{~s}$ time break was included for cells to recover fluorescence. For Quick-SIMBA of live ER, a continuous $405 \mathrm{~nm}$ laser was used to enhance the fluorescent signal. 10,000 sequential frames were taken at an exposure time of $5 \mathrm{~ms}$ (FOV: $760 \times 314$ pixels). Every other 50 frames, there is a 15 -ms dark recovery. Reconstructed images were generated using the Quick-SIMBA algorithm as detailed in Supplementary note.

\section{SSIM evaluation of PALM images}

The Structural SIMilarity (SSIM) index (Equation 9-12) was used to assess and compare the quality of PALM reconstructed images of U2OS cells overexpressing lifeact-pcStar and lifeact-mEos3.2 fusions. For each cell, a TIRF image in the green channel and 10 PALM stacks containing 5,000 frames each in the red channel were acquired. The SSIM values were calculated for PALM images reconstructed with gradually increasing stack numbers using the TIRF image as a reference. To compute the similarity under the same resolution, we rescaled the PALM images by blurring them with the PSF of the optical systems. A sliding window with $11 \times 11$ pixels was applied each time to compute a subregion, and values from all sub regions were subsequently averaged to attain the final SSIM value.

$$
\begin{aligned}
& \operatorname{SSIM}(\mathrm{x}, \mathrm{y})=\sum_{i, j \in \Omega} l(i, j) c(i, j) s(i, j) \\
& l(\mathrm{x}, \mathrm{y})=\frac{2 \mu_{x} \mu_{y}+C_{1}}{\mu_{x}^{2}+\mu_{y}^{2}+C_{1}} \\
& \mathrm{c}(\mathrm{x}, \mathrm{y})=\frac{2 \sigma_{x} \sigma_{y}+C_{2}}{\sigma_{x}^{2}+\sigma_{y}^{2}+C_{2}}
\end{aligned}
$$


$\mathrm{s}(\mathrm{x}, \mathrm{y})=\frac{\sigma_{x y}+C_{3}}{\sigma_{x} \sigma_{y}+C_{3}}$

(Equation 12)

where $\mu_{x}, \mu_{y}$ are the mean values of image $\mathrm{x}$, image $\mathrm{y} ; \sigma_{x}{ }^{2},{\sigma_{y}}^{2}$ are the variance of image $\mathrm{x}$, image $\mathrm{y} ; \sigma_{x} \sigma_{y}$ is the covariance of image $\mathrm{x}$ and image $\mathrm{y} ; C_{1}, C_{2}$ are constant values, $C_{1}=\left(k_{1} L\right)^{2}, C_{2}=\left(k_{2} L\right)^{2}$ where $k_{1}=0.01, k_{2}=0.03$ and $\mathrm{L}$ is the maximum intensity of the pixel; for 8-bit images, the value is 256 . The value of SSIM ranges from -1 to 1. A higher score indicates more similarities between the two images. To calculate the exponential convergence time $\left(\tau_{1 / \mathrm{e}}\right)$ for each cell, the SSIM curve was fitted to the first-order exponential decay using Equation 13.

$y(x)=y_{0}+A_{1} e^{-\frac{x}{t 1}}$

\section{(Equation 13)}

\section{Statistics}

The statistical significance of the data was calculated with Microsoft Excel, Microsoft Office 2013, and the data are shown as the mean \pm s.d. To compare two groups, we applied a pair-wise two-tailed t-test assuming unequal variance. All $\mathrm{P}$ values less than 0.05 were considered to be significant. 


\section{Supplementary Note2: Quick-SIMBA algorithm}

Same as SIMBA, Quick-SIMBA also requires two types of dataset that are obtained by time-lapse imaging of a photoconvertible fluorescent protein (PCFP) in two emission channels. The dataset from the channel before photoconversion contains high-density overlapping molecules with on/off or blinking and bleaching phenomena for Bayesian calculation; and another dataset is a collection of single molecules imaged from the channel after photoconversion, which will guide and assist the Bayesian calculation. The single molecules were precisely localized by single molecule localization algorithm and were randomly selected to compose the initial model for Bayesian calculation at first, then were combined with positive molecules from last iteration to compose a pool from which the candidate molecules were randomly selected for next iteration of Bayesian calculation. The more single-molecule recorded in the channel after photon-conversion, the higher chances they will occupy the model pool, the quicker and more accurate the reconstruction process will be.

The Quick-SIMBA workflow is shown below:

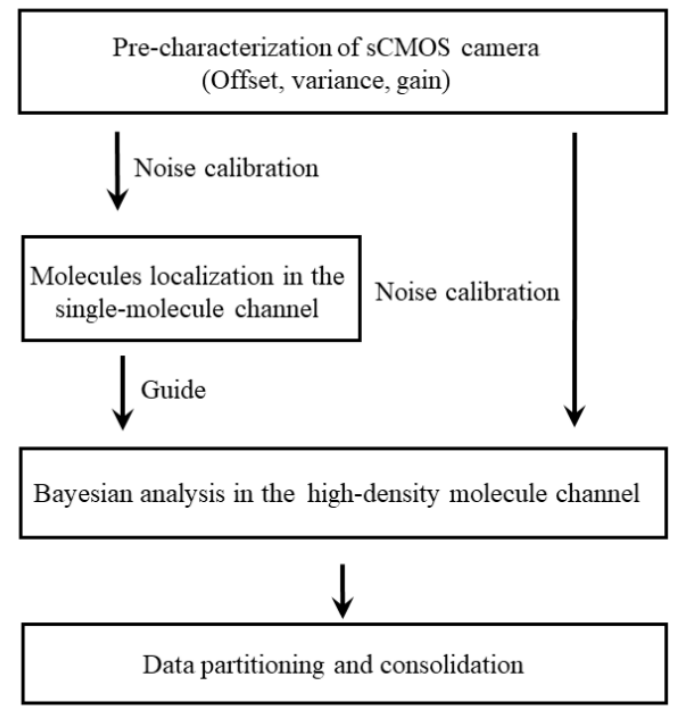

The detailed steps of Quick-SIMBA algorithm are as follow:

Step 1. Pre-characterization of the noise variance, offset and gain of the sCOMS camera 
Step 2. Single molecular localization information extraction in the single molecular channel

a) sCOMS calibration of the single molecular data

b) Fitting with the MLE $\mathrm{SCMOS}_{\mathrm{S}}$ (maximum likelihood estimation for SCMOS) algorithm to obtain each single molecule's localization information.

Step 3. Model selection: candidate molecules that are not too close with each other are randomly selected from the single molecules obtained in Step 2 for the initial model.

Step 4. Optimizing the initial model in the high-density molecule channel:

a) All molecules in the initial model are clustered in the initial model by k-means algorithm.

b) For each cluster,

i. Samplings of the initial model are conducted using the hybrid MCMC algorithm and the limited forward algorithm to find the best match between the model and the raw data.

ii. From each molecule, 6 newly optimized pending positions are calculated using the limited forward algorithm and the modified conjugate gradient method.

iii. Based on the distance and intensity thresholds, a determination is made whether to keep or drop the pending position as candidate molecules.

iv. Reserved molecules were added to the initial model and expansion sampling of the new molecule are performed.

Step 5. Go to Step 3.

Step 6. Data partitioning and consolidation. Split the raw data into two parts, for each part go to Step 2

Note that single molecules are processed in the red channel (Step 2). We utilized these molecules as initial candidates to gradually expand the candidate molecules in the green channel (Step 2 and Step 4). The algorithm was terminated when the adjacent reconstructed images were no longer significantly differed. 
Compared with SIMBA, the Quick-SIMBA algorithm has two major improvements: 1) Noise calibration enabling faster sample acquisition with sCMOS than EMCCD; In order to increase the temporal resolution, the sCMOS camera with fast readout speed for large FOV was employed. Since the sCMOS camera has pixel-dependent readout noise, which will introduce artifacts in SIMBA reconstruction, a pre-characterization and subsequent calibration of the camera were performed; 2) Data partitioning and consolidation ensuring reduction of raw frames for reconstruction. SIMBA took advantage of the on/off and bleaching properties of PCFPs that lead to signal fluctuation during time-lapse imaging. As on/off and bleaching of different molecules happened at different time points and for one particular molecule the time scale of appearance/disappearance is much shorter than the duration of the whole image sequence, we speculated that using sub image sequences with shortened image length will help to identify more molecules. Thus, we fist divided the whole image sequence into two equal parts, and then applied Quick-SIMBA algorithm to the two subsequences together with the full-length image individually, a final combination of the results from these three sequences will greatly increase the chance to identify more molecules with higher precision.

In addition, there are small modifications to further optimize the reconstruction performance of Quick-SIMBA. First, both SIMBA and Quick-SIMBA use the hybrid Markov chain Monte Carlo (MCMC) and the limited forward algorithm to sample the initial model to find the best match to the raw data iteratively. While SIMBA uses the averaged sample of each iteration to calculate the differences between the sample and the raw image data, Quick-SIMBA uses the best match sample to compare with the raw image data. Second, when conducting expansion sampling, the number of pending positions around each molecule that will be calculated and added to the initial model, turned from a fixed 4 in SIMBA to be adjustable (default is 6) in Quick-SIMBA. Third, a distance threshold (Dist overlap $_{\text {}}$ ) has been added when sampling the initial model made up of single molecules. Molecules that are within a certain distance will not be selected to ensure the distribution of single molecules in the initial model is as dispersed as 
possible, thus the single molecules in darker areas have more opportunities to be optimized.

The detailed method for Quick-SIMBA were as follow:

1. Pre-characterization of camera noise variance, offset and gain First, the auto-calibration function of the Prime95B sCMOS camera was shut down and 60,000 frame dark images were obtained to calculate the camera's variance Var and offset $O$ as shown in (1) and (2).

$$
\begin{aligned}
& \operatorname{Var}_{i}=\frac{1}{N} \sum_{s=1}^{N}\left(p_{i x}^{S}-O_{i}\right)^{2} \\
& O_{i}=\frac{1}{N} \sum_{S=1}^{N} p_{i} x_{i}^{S}
\end{aligned}
$$

where $\mathrm{N}$ is the total number of frames of the all black image, and pix $x_{i}^{s}$ is the photon number of the $i$ th pixel of the $s$ th frame.

For the Gain $g$ of the sCMOS camera, 20,000 image frames under 15 sets of different illumination intensities equally spaced among 20-200 ADU were collected. Then least squares linear fit were performed with the variance and the mean for each set to estimate the gain for each pixel according to (3).

$$
\hat{g}_{i}=\operatorname{argmin} \sum_{k=1}^{K}\left(\left(v_{i}^{k}-\operatorname{Var}_{i}\right)-g_{i}\left(\operatorname{Mean}_{i}^{k}-O_{i}\right)\right)^{2}
$$

As shown in Fig. S13, the noise variance of the Prime95B sCMOS camera is within the range of $0-50 \mathrm{ADU}^{2}$ with a mean of 3.37; the offset is between 97.5 $\mathrm{ADU}$ and 101.5 ADU with a mean of 100.04; the amplification gain varies from 1.2 to 2.4 ADU/e- with a mean of 1.38 .

\section{2. sCMOS calibration}

Calibration of the single molecular data and the high-density molecular data were conducted separately. The red channel single-molecule data is subtracted from the corresponding offset, and then divided by the gain as the raw data for single-molecule extraction. When performing Gaussian fitting, the MLE $\mathrm{s}_{\mathrm{s} M O S}$ (maximum likelihood 
estimation for sCMOS) algorithm was used ${ }^{19}$. Then dual channel registration was performed with the assistant of the fluorescent beads.

For Bayesian analysis, the corresponding offset is subtracted from each pixel in the green channel. Then, a high-pass filtering is performed before dividing the data by gian. The intensity distribution of each single molecule, described as point spread function (PSF), is modeled by Gaussian distribution in (4) and (5),

$$
\begin{aligned}
& \mu(x, \phi)=\frac{\phi_{1}}{\phi_{2} \sqrt{2 \pi}} e^{s} \\
& s=-\frac{\left(x_{1}-\phi_{3}\right)^{2}+\left(x_{2}-\phi_{4}\right)^{2}}{2 \phi_{2}}
\end{aligned}
$$

Here, $\mu(x, \phi)$ is the function of PSF, of which the intensity is $\phi_{1}$, the width parameter is $\phi_{2}$ and the center positon is $\phi_{3}, \phi_{4}$.

During the SIMBA reconstruction, the observation probability is calculated by comparing the log distribution of the differences between the data $I(x)$ and PSF model $\mu(x, \phi)$ in each pixel. The image noise is modeled as Gaussian with zero mean and the deviation (Var) of 1. The difference between Data and PSF model is as in (6):

$$
\begin{aligned}
& P(\text { image })=\prod_{x \in \text { pixels }} \frac{1}{\operatorname{Var} \sqrt{2 \pi}} e^{-\frac{(I(x)-\mu(x, \phi))^{2}}{2 \operatorname{Var}}} \\
& \ln P(\text { image })=\sum_{x \in \text { pixels }}-\frac{(I(x)-\mu(x, \phi))^{2}}{2 \operatorname{Var}}-\frac{N}{2} \ln 2 \pi \operatorname{Var}
\end{aligned}
$$

Here, $P($ image $)$ is the difference between the data and model in a certain image region. $\ln P($ image $)$ is the log distribution of $P($ image $) . \mathrm{N}$ is the number of the pixels in a certain image region.

Then, the derivation of the observation probability is calculated as in (8) to find the best match of the data and model by using the conjugate gradient method ${ }^{20}$.

$\frac{\partial \ln P(\text { image })}{\partial \emptyset}=\frac{1}{V a r} \sum_{x \in \text { pixels }}(I(x)-\mu(x, \phi)) \frac{\partial}{\partial \emptyset} \mu(x, \phi)$

However, in Quick-SIMBA, rather than using the uniform variance model, the sCMOS variance model was applied when calculating the observation probability (9-11). It can 
be concluded from Fig. S14 that sCMOS calibration significantly reduces artifacts caused by sCMOS pixel-dependent readout noise.

$P($ image $)=\prod_{x \in \text { pixels }} \frac{1}{\frac{\operatorname{Var}(x)}{g^{2}(x)} \sqrt{2 \pi}} e^{-\frac{(I(x)-\mu(x, \phi))^{2}}{2 \frac{\operatorname{Var}(x)}{g^{2}(x)}}}$

$\ln P($ image $)=\sum_{x \in \text { pixels }}-\frac{(I(x)-\mu(x, \phi))^{2}}{2 \frac{\operatorname{Var}(x)}{g^{2}(x)}}-\frac{N}{2} \ln 2 \pi \frac{\operatorname{Var}(x)}{g^{2}(x)}$

$\frac{\partial \ln P(\text { image })}{\partial \emptyset}=\frac{1}{\frac{\operatorname{Var}(x)}{g^{2}(x)}} \sum_{x \in p i x e l s}(I(x)-\mu(x, \phi)) \frac{\partial}{\partial \emptyset} \mu(x, \phi)$

Here, $\operatorname{Var}(\mathrm{x}), \mathrm{g}(\mathrm{x})$ is the pixel-dependent variance and gain in sCMOS camera.

\section{Validation of sCMOS calibration}

First, to verify that the pre-measured calibration parameters has the same distribution in the raw image we acquired in the real experiment, we did an alignment test. As shown in Fig. S14, the standard deviation map (Fig. S14b) of cell expression lifeactpcStar was calculated and aligned to the noise variance map of the sCMOS camera measured under dark condition (Fig. S14c). It can be clearly seen that those pixels with high variances coincided very well in the two maps (Fig. S14d \& S14f). While in contrast, when the calibration parameters were applied to the wrong pixels, the colocalizations will be very poor (Fig. S14e \& S14f), indicating the perfect alignment of the calibration parameters.

Next, to validate the calibration algorithm, in silico data of concentric circles containing pixel-dependent noise were reconstructed using the original SIMBA algorithm with or without calibration. Noises and artifacts were completely eliminated by sCMOS calibration, demonstrating the functionality of the calibration method (Fig. S15a \& S15b).

4. Data partitioning and consolidation 
Data partitioning and consolidation strategy was performed as shown in Fig. 16a: first, two sub-sets of the whole image sequences (0-24 frames, 25-49 frames) and the whole image sequences containing 50 frames were reconstructed separately by Quick-SIMBA; then, the difference map of the reconstruction results between sub-set A or B and the whole image sequences were calculated, after which all the negative values were filtered out, leaving positive signals appeared in the sub-set sequence as shown in Diff A or Diff B; finally, the reconstruction results from Diff A, Diff B and Recon All were combined to obtain the final result.

5. Validation of data partitioning and consolidation

We validated the data partitioning and consolidation strategy by comparing reconstructed results from Original SIMBA, Quick-SIMBA with and without data partitioning and consolidation by using in silico data (Fig. S15c). Images reconstructed by Quick-SIMBA algorithm from 50 raw frames were as good as that reconstructed by Quick-SIMBA algorithm without data partitioning and consolidation from 200 raw frames, and was clearly better than that reconstructed by Quick-SIMBA algorithm without data partitioning and consolidation from 50 raw frames or by original SIMBA algorithm from 200 raw frames.

\section{REFERENCE}

(1) Costantini, L. M.; Fossati, M.; Francolini, M.; Snapp, E. L. Assessing the tendency of fluorescent proteins to oligomerize under physiologic conditions. Traffic 2012, 13, 643-9.

(2) Guo, Y. T.; Li, D.; Zhang, S. W.; Yang, Y. R.; Liu, J. J.; Wang, X. Y.; Liu, C.; Milkie, D. E.; Moore, R. P.; Tulu, U. S.; Kiehart, D. P.; Hu, J. J.; LippincottSchwartz, J.; Betzig, E.; Li, D. Visualizing Intracellular Organelle and Cytoskeletal Interactions at Nanoscale Resolution on Millisecond Timescales. Cell 2018, 175, 1430-+.

(3) Huang, X.; Fan, J.; Li, L.; Liu, H.; Wu, R.; Wu, Y.; Wei, L.; Mao, H.; Lal, A.; Xi, P.; Tang, L.; Zhang, Y.; Liu, Y.; Tan, S.; Chen, L. Fast, long-term, super-resolution imaging with Hessian structured illumination microscopy. Nat Biotechnol 2018, 36 , 451-459. 
(4) Nixon-Abell, J.; Obara, C. J.; Weigel, A. V.; Li, D.; Legant, W. R.; Xu, C. S.; Pasolli, H. A.; Harvey, K.; Hess, H. F.; Betzig, E.; Blackstone, C.; LippincottSchwartz, J. Increased spatiotemporal resolution reveals highly dynamic dense tubular matrices in the peripheral ER. Science 2016, 354.

(5) Zhang, M.; Chang, H.; Zhang, Y.; Yu, J.; Wu, L.; Ji, W.; Chen, J.; Liu, B.; Lu, J.; Liu, Y.; Zhang, J.; Xu, P.; Xu, T. Rational design of true monomeric and bright photoactivatable fluorescent proteins. Nature methods 2012, 9, 727-9.

(6) Chudakov, D. M.; Lukyanov, S.; Lukyanov, K. A. Tracking intracellular protein movements using photoswitchable fluorescent proteins PS-CFP2 and Dendra2. Nat Protoc 2007, 2, 2024-2032.

(7) Wang, S.; Moffitt, J. R.; Dempsey, G. T.; Xie, X. S.; Zhuang, X. Characterization and development of photoactivatable fluorescent proteins for single-molecule-based superresolution imaging. Proceedings of the National Academy of Sciences of the United States of America 2014, 111, 8452-7.

(8) Kaberniuk, A. A.; Mohr, M. A.; Verkhusha, V. V.; Snapp, E. L. moxMaple3: a Photoswitchable Fluorescent Protein for PALM and Protein Highlighting in Oxidizing Cellular Environments. Sci Rep 2018, 8, 14738.

(9) Zhang, X.; Zhang, M.; Li, D.; He, W.; Peng, J.; Betzig, E.; Xu, P. Highly photostable, reversibly photoswitchable fluorescent protein with high contrast ratio for live-cell superresolution microscopy. Proceedings of the National Academy of Sciences of the United States of America 2016, 113, 10364-9.

(10)Huang, J.; Zhou, W.; Dong, W.; Watson, A. M.; Hong, Y. Directed, efficient, and versatile modifications of the Drosophila genome by genomic engineering.

Proceedings of the National Academy of Sciences 2009, 106, 8284-8289.

(11) Yu, Z.; Chen, H.; Liu, J.; Zhang, H.; Yan, Y.; Zhu, N.; Guo, Y.; Yang, B.; Chang, Y.; Dai, F. Various applications of TALEN-and CRISPR/Cas9-mediated homologous recombination to modify the Drosophila genome. Biology open 2014, 3, 271-280.

(12)Andresen, M.; Stiel, A. C.; Folling, J.; Wenzel, D.; Schonle, A.; Egner, A.; Eggeling, C.; Hell, S. W.; Jakobs, S. Photoswitchable fluorescent proteins enable monochromatic multilabel imaging and dual color fluorescence nanoscopy. Nat Biotechnol 2008, 26, 1035-40.

(13)Chudakov, D. M.; Verkhusha, V. V.; Staroverov, D. B.; Souslova, E. A.; Lukyanov, S.; Lukyanov, K. A. Photoswitchable cyan fluorescent protein for protein tracking. Nature biotechnology 2004, 22, 1435.

(14)Subach, O. M.; Patterson, G. H.; Ting, L. M.; Wang, Y.; Condeelis, J. S.; Verkhusha, V. V. A photoswitchable orange-to-far-red fluorescent protein, PSmOrange. Nature methods 2011, 8, 771-7.

(15)Murphy, K. C.; Campellone, K. G. Lambda Red-mediated recombinogenic engineering of enterohemorrhagic and enteropathogenic E. coli. BMC molecular biology 2003, 4, 11.

(16)Pu, Y.; Li, Y.; Ma, Q.; Tian, T.; Zhao, Z.; McVey, A.; Bai, F. Dynamic protein aggregation regulates bacterial dormancy depth critical for antibiotic tolerance. bioRxiv 2017, 233890. 
(17)Sun, Y.; Fei, T.; Yang, T.; Zhang, F.; Chen, Y.-G.; Li, H.; Xu, Z. The suppression of CRMP2 expression by bone morphogenetic protein (BMP)-SMAD gradient signaling controls multiple stages of neuronal development. Journal of Biological Chemistry 2010, 285, 39039-39050.

(18)Xu, F.; Zhang, M.; He, W.; Han, R.; Xue, F.; Liu, Z.; Zhang, F.; LippincottSchwartz, J.; Xu, P. Live cell single molecule-guided Bayesian localization super resolution microscopy. Cell Res 2017, 27, 713-716.

(19)Huang, F.; Hartwich, T. M.; Rivera-Molina, F. E.; Lin, Y.; Duim, W. C.; Long, J. J.; Uchil, P. D.; Myers, J. R.; Baird, M. A.; Mothes, W.; Davidson, M. W.; Toomre, D.; Bewersdorf, J. Video-rate nanoscopy using sCMOS camera-specific singlemolecule localization algorithms. Nature methods 2013, 10, 653-8.

(20)Press, W. H.; Teukolsky, S. A.; Vetterling, W. T.; Flannery, B. P., Numerical Recipes in C, 2nd edn 724-732. Cambridge Univ. Press, Cambridge: 1999. 